\title{
HISTORIA
}

\section{El tifus exantemático en Jerez de la Frontera (1941-1942)}

The exanthematic typhus in Jerez de la Frontera (1941-1942)

O tifo exantemático em Jerez de la Frontera (1941-1942)

\section{Francisco Herrera-Rodríguez ${ }^{1}$}

${ }^{1}$ Catedrático E.U. (jubilado) de la Facultad de Enfermería y Fisioterapia. (Universidad de Cádiz). Correo electrónico: fraherod57@gmail.com

Cómo citar este artículo en edición digital: Herrera- Rodríguez, F. (2020). El tifus exantemático en Jerez de la Frontera (1941-1942). Cultura de los Cuidados (Edición digital), 24 (57) Recuperado de http://dx.doi.org/10.14198/cuid.2020.57.08

Correspondencia: C/Santo Domingo de la Calzada, $n^{\circ} 11-3^{\circ}$ A. 11012-Cádiz

Correo electrónico de contacto: fraherod57@gmail.com

Al profesor Dr. D. Antonio Orozco Acuaviva, en el vigésimo aniversario de su fallecimiento.

Y a los profesionales sanitarios que en estos tiempos de Coronavirus se dejan la piel y la vida cuidando a todos los que lo necesitan, sin tener los medios de protección requeridos. Muchas gracias.

"En las esquinas urbanas, las estraperlistas daban la cara, más o menos limpia, por otros que la escondían en la nocturnidad de las lanchas y de los pasos fronterizos organizados. Cuando los trenes llegaban a las ciudades, en las cercanías, los traficantes del hambre lanzaban la mercancía por la ventana para eludir el control aduanero en cada estación".

Manuel Vázquez Montalbán, Crónica sentimental de España 


\begin{abstract}
The objectives of this paper are to locate documentation to study the morbidity and mortality caused by exanthematous typhus in Jerez de la Frontera (1941-1942); to study the sanitary measures that were carried out in this city against this disease, and to point out other problems of morbidity and mortality in the 1940s.
\end{abstract}

Keywords: exanthematous typhus, epidemic, Postwar period, Spain, Cádiz Province, Jerez de la Frontera, Twentieth century, José Estrade Camúñez, Donato Fuejo García, Salvador Dastis.

\section{RESUMEN}

Los objetivos de este trabajo son: localizar documentación para estudiar la morbilidad y la mortalidad ocasionada por el tifus exantemático en Jerez de la Frontera (1941-1942); estudiar las medidas sanitarias que se llevaron a cabo en esta ciudad contra esta enfermedad, y exponer otros problemas de morbilidad y mortalidad en los años 40 .

Palabras clave: Tifus exantemático, epidemia, Posguerra, España, Provincia de Cádiz, Jerez de la Frontera, Siglo XX, José Estrade Camúñez, Donato Fuejo García, Salvador Dastis.

\section{RESUMO}

Os objetivos deste trabalho são documentação para estudar a morbimortalidade causada por tifo exantematoso em Jerez de la Frontera (19411942); estudar as medidas sanitárias adotadas nesta cidade contra essa doença e expor outros problemas de morbimortalidade na década de 1940.

Palavras-chave: tifo exantemático, epidemia, Pós-guerra, Espanh, Província de Cádis, Jerez de la Frontera, Século XX, José Estrade Camúñez, Donato Fuejo García, Salvador Dastis.
En trabajos anteriores hemos dedicado estudios a la posguerra, centrados en el tifus exantemático y en la sanidad municipal gaditana, también hemos glosado aspectos literarios relacionados con la literatura, la medicina y la enfermería (HerreraRodríguez, 1997; 2000; 2001; 2005; 2008; 2015; 2018). A la primera línea mencionada, la del tifus exantemático en la posguerra, dedicamos este artículo, tratando de complementar nuestro estudio anterior (1997), pero en esta ocasión centrando los esfuerzos en la ciudad de Jerez de la Frontera (Cádiz), donde también se padeció esta enfermedad.

Los objetivos, pues, de este trabajo son los siguientes:

-Localizar documentación para estudiar la morbilidad y la mortalidad ocasionada por el tifus exantemático en Jerez de la Frontera en la posguerra.

-Estudiar las medidas sanitarias que se llevaron a cabo en Jerez para luchar contra el tifus exantemático en los años 40 .

-Exponer otros problemas de morbilidad y mortalidad en el Jerez de los años 40.

En los trabajos mencionados hemos realizado síntesis sobre la posguerra en España, motivo por el que remitimos a ellos para no repetirnos, presentando aquí algunos datos históricos básicos sobre esos duros años en España, que nombramos como Posguerra, posteriores a la Guerra Civil, que 
tanto padecieron nuestros padres y abuelos, también en la bibliografía incluimos algunas referencias bibliográficas sobre el tema, que consideramos de interés, aunque como es sabido la bibliografía sobre el particular es muy extensa (Abella, 1996; Barciela, 2000; Caballero Bonald, 1995; Eslava Galán, 2010; García-Delgado, 2000; Harrison, 1991; Juliá, 2008; Millán Chivite, 1993; Tamames, 1985; Terán Reyes, 2012; Vázquez-Montalbán, 1986). Y específicamente sobre el tifus exantemático en la posguerra se deben destacar al menos los trabajos de Jiménez Lucena (1990 y 1994); Rodríguez Ocaña (2017); García Ferrandis y Martínez-Vidal (2017 y 2019); Marín-Paz (2017), y como hemos indicado el trabajo monográfico que dedicamos a la incidencia de esta enfermedad en la ciudad de Cádiz (1997).

Diversos autores han señalado que "durante la Guerra fueron prioritarias las necesidades de sueros y vacunas, la lucha contra las enfermedades venéreas, y la lucha antipalúdica y al acabar la contienda (...) la extensión de tres grandes epidemias centraron los esfuerzos sanitarios del régimen de Franco: viruela, tifus exantemático y difteria" (Marset Campos, P.; Rodríguez Ocaña, E.; Sáez Gómez, J.M., 1998). Téngase en cuenta que la Dirección General de Sanidad, en los años 40, mostró su preocupación por el tifus exantemático, sobre todo lo cual insistiremos en apartados posteriores en este artículo (Palanca, 1943; Jiménez Lucena, 1990 y 1994; HerreraRodríguez, 1997).
En su conjunto la tendencia fue la del aumento de la mortalidad por enfermedades infecciosas, sirva como ejemplo que en 1936 se produjeron 19.937 defunciones por tuberculosis pulmonar y 5.165 por otras tuberculosis, mientras que en 1941 las cifras fueron, respectivamente, de 26.663 y 6.146 (Palanca, 1943). Sin olvidarnos en lo que se refiere a la nutrición que la realidad de aquellos años estuvo presidida por la escasez de alimentos básicos como el pan, la leche, el azúcar y el aceite; escaseó también el jabón, tan necesario para la higiene (Millán Chivite, 1993), como tendremos ocasión de comprobar en este artículo. Sobre la alimentación y el hambre, en este periodo, la pelagra y el latirismo, se debe consultar a Del Cura y Huertas (2007), asimismo se ha apuntado que la irracional política económica autárquica fue la principal responsable del estancamiento económico y de la larga crisis de subsistencia (Arco Blanco, 2006).

Se debe tener en cuenta también que la tasa de mortalidad infantil se elevó de 109 defunciones por mil nacidos vivos, en 1940, a 143 en el año 1941, descendiendo en 1942 a 103, a 99 en 1943, a 93 en 1944 y a 85 en 1945 (Arbelo Curbelo, 1962; Gómez Redondo, 1992).

Pero antes de entrar en el desarrollo de los objetivos de este trabajo, centraremos nuestros comentarios en la Posguerra en Jerez de la Frontera.

1.-Datos generales sobre la Posguerra en Jerez de la Frontera 
Revista científica de la Asociación de Historia y Antropología de los Cuidados (Universidad de Alicante)

Se ha señalado que la población jerezana en 1940 era de 89.525 habitantes y que en 1950 ascendía ya a 105.467 (Caro Cancela, 1999), como se puede comprobar un significativo ascenso poblacional entre las dos fechas, que podemos matizar aún más gracias a la documentación existente en el Archivo Municipal de Jerez que exponemos en la tabla I, en la que aparecen las cifras de la población de los años 1940 a 1950.

Un aspecto que no podemos perder de vista, en España en general como específicamente en Jerez de la Frontera, es el del mercado negro, la miseria y el aislamiento entre los años 1939 y 1953. Apunta al respecto Caro Cancela, citando a otros autores, lo siguiente (1999):

“Terminada la Guerra Civil (...), el fenómeno más característico de la España de los años cuarenta fue el 'estraperlo', esto es, la aparición de un amplio mercado negro que afectó a todo tipo de productos, pero especialmente a los alimenticios. Su origen hay que situarlo en la escasez que se produce de algunos artículos (...). El racionamiento crea un deseo de adquirir cantidades adicionales de bienes al margen del mercado legal, lo que favorece la aparición de productores dispuestos a satisfacer esa demanda a precios superiores a los 'oficiales'. De esta manera, el estraperlo y la especulación surgen como consecuencia de la intervención del Estado en la economía, por la creencia de los gobernantes de que los precios se podían regular por decreto, mediante el sencillo recurso de prohibir que se subieran".

El propio Caro Cancela apunta "que estas prácticas también se produjeron en Jerez de la Frontera". El periódico jerezano, “Ayer”, en la década de los cuarenta publicó con frecuencias notas con la tasación de los productos básicos, en este sentido además de lo apuntado por el autor citado, exponemos algunos ejemplos sobre racionamiento de productos básicos y cartillas de racionamiento, referidos al aceite, a las patatas y a las cartillas de racionamiento extraviadas (“Ayer”, 15-VI-1941):

“A partir del próximo Martes 17 del actual y en el plazo no superior a diez días, todos los poseedores de cartillas de racionamiento de comestibles, podrán retirar de los respectivos establecimientos a que aquéllas estén adscritas, contra entrega del cupón núm. 155 de Ultramarinos, un cuarto de litro de aceite, por cada persona, al precio de 4,15 pesetas el litro, (...), podrán retirar contra entrega del cupón número 153 de Ultramarinos, un kilogramo de patatas por persona, al precio de 1 peseta el kilogramo (...). Ante los numerosos casos de pérdidas de cupones de las cartillas de racionamientos, se recuerda una vez más a los dueños de establecimientos de comestibles y despachos de pan, la prohibición absoluta que tienen de facilitar los artículos correspondientes, como no sea que vayan los cupones adheridos cada uno a su cartilla. El incumplimiento de esta orden será debidamente sancionado (...). 
Cultura de los Cuidados

Habiéndose observado la frecuencia con que se extravían las cartillas (...). Esta Alcaldía advierte que cualquiera de estos casos que se compruebe será sancionado con el encarcelamiento de aquellos que tal hecho cometan, siendo castigadas con la misma sanción todas aquellas personas que se encuentran cartillas de racionamiento y no las entregas seguidamente en las oficinas de esta Delegación. Por Dios, por España y su Revolución Nacional Sindicalista. Jerez de la Frontera 15 de junio de 1941".

La Delegación Local de Abastecimientos y Transportes anunciaba en la prensa, a los poseedores de cartillas de racionamiento, que 200 gramos de azúcar por persona se expende a 3 pesetas el kilo (“Ayer", 9-V-1941). En la prensa, esta misma Delegación, anunció la entrada en vigor de las nuevas cartillas a efecto de suministro de pan: la ración de primera categoría, 80 gramos, a 0,10 pesetas la pieza; la ración de segunda categoría, 120 gramos, 0,15 pesetas la pieza, y la ración de tercera categoría, 150 gramos, a 0,15 pesetas la pieza (“Ayer”, 16-V-1941).

En estas mismas fechas la prensa jerezana inserta una brevísima nota de prensa recordando el veintiún aniversario de la muerte de Joselito el "Gallo" en Talavera de la Reina, incluyendo oraciones por su alma: "Recemos un Padrenuestro por el eterno descanso de su alma, como el mejor y más piadoso homenaje a su memoria”. El mismo periódico anunció la actuación de Conchita Piquer, con foto de perfil de la artista, en el Teatro Villamarta, con su espectáculo "Arte Andaluz" (“Ayer”, 20-V-

1941). Toros, coplas y sobre todo racionamiento.

En esos mismos días, don Manuel de Mora-Figueroa y Gómez-Imaz, Gobernador civil de la provincia publicó un Bando en el que anunciaba que quedaba intervenida toda la cosecha de patata, "a disposición de mi autoridad, que oportunamente fijará el precio". Y se añade en la noticia de prensa: "El incumplimiento de lo preceptuado en este Bando, será castigado con el máximo rigor, lo que se hace público en evitación de que pueda alegarse ignorancia, quedando los alcaldes obligados a dar la mayor publicidad al mismo, y asumiendo la responsabilidad que por causa de desobediencia o desconocimiento pudieran derivarse. Cádiz 9 de mayo de 1941. El Gobernador Civill". Igualmente, en este periódico jerezano, se advierte que la intervención e inmovilización de la patata no es exclusiva para el "tubérculo" de siembra, sino que es extensivo a toda la patata o de primera cosecha (“Ayer", 18-V-1941).

Es sabido que el año 1940 fue conocido como "el año del hambre", hay que tener en cuenta que entre 1936 y 1946 los salarios sólo se habían doblado, mientras el coste de la vida se había multiplicado por cuatro. Todo ello apunta a la miseria en que vivieron las clases populares, que sufría el estraperlo, la adulteración de productos, el pan negro, y tantas otras calamidades. Al parecer en Jerez se afirmaba que los caballos de la gente adinerada comían mejor que las personas, ya que eran alimentados con habas y garbanzos 
Revista científica de la Asociación de Historia y Antropología de los Cuidados (Universidad de Alicante)

(Ruiz Mata, 2010). El escritor jerezano Caballero Bonald, en su obra "Tiempo de guerras perdidas" (1995), ofrece detalles del estado lastimoso de la población durante la guerra y la posguerra, del hambre y el frío en el paisaje social de Jerez. Léase lo que apuntamos en los siguientes párrafos:

"Me acuerdo, por ejemplo, de esas gentes desesperadas y famélicas que llamaban (...) a la puerta de casa. No eran pobres limosneros, eran mujeres dignas que pedían un trozo de pan o una vieja prenda de abrigo (...). Fue cuando la desnutrición fomentó las epidemias de tifus, de tuberculosis, de pelagra, y yo oía decir que todos acabaríamos siendo víctimas de alguna incurable enfermedad (...). Vi a dos niños harapientos cazando un gato, a una anciana temblorosa masticando un puñado de gramíneas silvestres, a un hombre que no parecía un mendigo envuelto en una andrajosa manta cuartelera...".

El periódico jerezano, el día 1 de abril de 1941, publicó en la primera página la efemérides del Segundo Aniversario del día de la Victoria, con fotografía de perfil y severa del Caudillo, anunciando también una misa en la Iglesia de San Miguel "por los Caídos en la Cruzada heroica que volvió a nuestra Patria a sus rutas imperiales" (“Ayer", 1-IV-1941). Se publica asimismo que el número premiado en el cupón de ciegos es el 763 y que la temperatura máxima fue de $14,8^{\circ}$. Y ese mismo día se ofrece noticia sobre el jabón, que puede tener interés para este artículo en lo que se refiere a la higiene y el tifus exantemático:

"Todos los industriales drogueros de esta Ciudad, deberán remitir en el día de mañana a estas Oficinas, declaración jurada expresiva de las existencias de jabón, sobrantes de racionamiento, que obren en poder de los mismos, acompañando los cupones acreditativos de las entregas efectuadas, así como nota expresiva del número total de personas inscritas en cada droguería hasta la fecha. Por Dios, por España y su Revolución NacionalSindicalista. Jerez de la Frontera, 1 de abril de 1941".

Caro Cancela, apoyándose en otros autores y en sus investigaciones, apunta que “el sistema benefició, más que a los pequeños agricultores, a los grandes terratenientes, que contaron con todo lo necesario para participar en el mercado negro...". Señala también que estas prácticas se produjeron en Jerez de la Frontera.

El Hospital Municipal de Santa Isabel fue la institución asistencial jerezana más importante, pasando a lo largo de su historia por muchas dificultades económicas (Orellana González, 1996). Mariscal Trujillo ha señalado la situación lastimosa que se vivió en este hospital en la posguerra (2001):

"Penosos fueron para el Hospital de Santa Isabel los años que siguieron a nuestra Guerra Civil. Del triste panorama de hambre, miseria y desolación que envolvió a nuestro país, no se libró este centro. Personas 
que allí trabajaron en estos años y a las que llegamos a conocer, fueron testigos de aquel sombrío panorama sanitario: salas abarrotadas de enfermos graves sin los más elementales medios para atenderlos. Faltaba comida, faltaban medicamentos, faltaba instrumental, faltaba jabón, apósitos, desinfectantes, faltaba de casi todo. Por decenas se podían contar los pobres desgraciados que llegaban a las puertas del Hospital desnutridos y moribundos, víctimas de disentería, cólera, tifus exantemático, tisis, escorbuto, paludismo, infecciones y otras muchas enfermedades propias de la miseria y el hambre. Aunque la mayor plaga sanitaria de estos años, (...), fue sin lugar a dudas la tuberculosis, agravada por tanta miseria y las peores condiciones higiénicas".

Recurrimos a otras fuentes documentales para comprobar que la situación era más que alarmante en lo que se refiere a la vida cotidiana y a la supervivencia, compruébese en la carta que el presbítero Rafael Serrano dirige, en 1941, al Alcalde de Jerez, José de Mora Figueroa (Marqués de Tamarón); copiamos tan solo unos párrafos del citado documento para dejar testimonio de una pequeña historia que abre en canal la vida tan dura padecida en la posguerra española, y en este caso concreto jerezana, transcribimos todo en letra minúscula, ya que el presbítero, probablemente en su desesperación hace acopio, en algunos fragmentos, de letras mayúsculas, fruto con seguridad de su desazón. Escribe lo siguiente el presbítero al alcalde jerezano (Cf. Carta Presbítero Rafael

Serrano al Alcalde de Jerez, 1941, AMJF):

“...Respetable y estimado, Don José, en Cristo (...). La naturaleza y condición del diálogo, no se presta de suyo a la exposición reposada y tranquila de los conceptos a dilucidar, y, por otra parte, sus múltiples atenciones y preocupaciones cada vez son mayores y más urgentes, (...) con el fin de no embargarle tiempo necesario para otras diligencias, dejándole en libertad de leerlo, cuando buenamente pueda (...). Sabe perfectamente, Querido Don José, que acabo de realizar solo, por el permiso de mi Compañero (....), la Campaña terrible de la Epidemia del Tifus (...), durante los cuarenta días habiendo hecho cincuenta y ocho entierros, ciento ochenta y cuatro administraciones de sacramentos, (....), veinticinco certificados gratuitos para los Comedores de Auxilio Social, a más de la Guardia permanente y la Misa diaria (....). No pido, ni exijo, ni dobles sueldos, ni dietas, ni gratificaciones y ni recompensas de ninguna clase, solo le pido, (....), una poco de atención y consideración, si la merezco, con el fin de que cuando las circunstancias lo permitan, tenga la bondad de ordenar, se me abonen los haberes atrasados (...) desde el año 1936, ratificados recientemente por ese Excmo. Ayuntamiento de su digna dirección y presidencia (...). El segundo favor, le suplico un poco de permiso, siquiera mes y medio, para descansar y reponer un poco las fuerzas y la salud del trabajo transcurrido en todo este año, que ha sido el más terrible en 
Revista científica de la Asociación de Historia y Antropología de los Cuidados (Universidad de Alicante)

los catorce años que llevo, en cuestión de Administraciones de enfermos y entierros verificados".

La carta del presbítero termina con el tradicional suyo afectísimo y s.s.q.e.s.m., e incluye la petición, “teniendo en cuenta la Epidemia", de que se le dote de elementos de aseo y limpieza indispensables ya que con motivo del ejercicio del Sagrado Ministerio debe estar en contacto con toda clase de enfermos. Y además añade en su carta al Alcalde:

“...le agradeceré infinito tenga la bondad de repasar, con los datos, que suministre la Intervención, la escala de sueldos y honorarios de los Funcionarios y Empleados, y verá con gran asombro, que los capellanes del Excmo. Ayuntamiento estamos a la cola de todas las escalas y categorías, percibiendo los sueldos y honorarios del año treinta y seis, a pesar de la desproporción enorme y cambio radical del coste de la vida de aquella fecha a esta parte, dándose la irritante $\mathrm{y}$ depresiva desigualdad y paradoja, de que siendo funcionarios jefes de negociado, en nuestra órbita funcional, percibimos menos sueldos que un simple portero".

Otro aspecto que nos ofrece una panorámica general de la situación en Jerez de la Frontera es el de la mortalidad, como se puede comprobar en la tabla 2 , realizada a partir de los datos ofrecidos por José Estrade Camúñez en las Memorias del Laboratorio Municipal de Higiene de Jerez de la Frontera (Cf. las Memorias utilizadas en el apartado de Fuentes documentales). En el año 1941, en Jerez, se producen 2.303 defunciones, presentando una tasa de mortalidad general ese año de 25,7 defunciones por mil habitantes, cifras muy superiores a las de los años 1937, 1938, 1939 y 1940. A partir de 1942 hasta 1945 las defunciones y las tasas van decreciendo, como puede comprobarse en la citada tabla, rompiéndose esta tendencia en 1946 que contabiliza 1.163 defunciones y una TMG de 12,9.

Como se puede apreciar en la tabla 3, referida a Cádiz capital y a la provincia de Cádiz, en 1941, también se produce una elevación de la TMG, presentando Cádiz capital 31,43 y la provincia 27,59. Tasas superiores a la de Jerez de la Frontera para ese mismo año que fue de 25,7 (tabla 2), aunque las tasas de Cádiz, de la provincia y de Jerez de la Frontera están por encima de la tasa de mortalidad general de España, en 1941, que fue de 18,69, y en 1940, de 16,30 (Palanca, 1943). Otro aspecto que debe subrayarse es que la tasa de mortalidad infantil en la provincia de Cádiz se elevó de 111,61 defunciones por mil nacidos vivos, en 1940, a la cifra de 198,28 en el año 1941 (Gómez Redondo, 1992). Sobre esta cuestión insistiremos en el Epílogo de nuestro trabajo.

Téngase en cuenta sobre Jerez de la Frontera, a modo de comparación, que entre 1837-1860 se produjeron 31.602 defunciones y que en relación a la población media de dicho periodo da una tasa de mortalidad media del 36,5 por mil (Conde 
González, 2003). Un periodo que nos interesa, por su cercanía al periodo de la Posguerra es el de los años 1930 a 1937, cuyos datos tomamos de la Memoria que redactó el médico Pedro Máximo Ruiz, quede constancia que en lo referido a este último año encontramos diferencias en las cifras con respecto a las ofrecidas por José Estrade Camúñez, y que fueron los años 1930,1933 y 1935 en los que las tasas de mortalidad fueron superiores en Jerez de la Frontera con 20,81; 20,80 y 21,51 defunciones por mil (Máximo Ruiz, 1937) (tabla 4).

Francisco Bejarano ofrece unos comentarios de interés en su obra "El Jerez de los bodegueros", que sirve de complemento a todo lo dicho sobre la situación social en la ciudad, aunque se centren más en la década de los sesenta, introduce matices que también podrían darse en la década de los 40 , pero con más intensidad y desenlaces fatales. Dice así (2004):

"Otra cosa son los años que van de 1936 a 1953. Mis recuerdos infantiles no llegan tan lejos, pero mi adolescencia fue de los años 60. España era católica y más española que nunca. Había mucha hipocresía en las clases medias y bajas y una vida un poco miserable, no tanto por la escasez que siguió a la guerra, sino por el espionaje de unos a otro y por el disimulo malicioso. A los bodegueros y a los labradores ricos no pareció afectarles la guerra. Tuvieron también sus muertos que recordar, pero su forma de vida no cambió hasta mediados los $50 "$.
Sería digno de rememorar, aunque no tenemos espacio en este artículo, cómo se ganaban la vida algunos artistas gitanos de Jerez, a principio de los años 40, y cómo compartían las alegrías y las penas en las casas los gitanos del Barrio de Santiago, dando pie por cualquier motivo insignificante a una fiesta. Así lo cuenta el gran guitarrista flamenco Manuel Morao: "No teníamos dinero para hacer otras cosas, pero teníamos esa convivencia, nacida de vivir todos juntos, que nos permitía compartir las alegrías y las penas. Y no necesitábamos más para que surgiera la fiesta y para que cada uno pusiera en ella lo mejor de su arte" (Suárez Japón, 2014). Y todo esto en una época de hambre, calamidades y epidemias.

\section{2.-Generalidades etiológicas y clínicas sobre el tifus exantemático}

Esta enfermedad ha recibido a lo largo de la historia diversas denominaciones, por ejemplo: morbi contagiosi, tabardillo pintado, fiebre infecciosa, fiebre pestilencial, tifus exantemático, por los autores alemanes, typhus, tifus castrense (Maradona Hidalgo, 2010). También ha sido denominada como tifus de los piojos (Haagen, 1942) o tifus de las cárceles (Martín Salazar, 1916).

Como se ha señalado, en 1909, ilustres médicos españoles de la Academia de Medicina seguían confundiendo la fiebre tifoidea con el tifus exantemático, cuando ya en 1837 se habían separado ambas entidades nosológicas (Marset Campo; Rodríguez 
Revista científica de la Asociación de Historia y Antropología de los Cuidados (Universidad de Alicante)

Ocaña; Sáez Gómez, 1998). Por este motivo no puede sorprender que en estas fechas se debatiera con intensidad el tema, sobre todo cuando en Madrid una epidemia de tifus exantemático generaba morbilidad $\mathrm{y}$ mortalidad. Un ejemplo, de lo que decimos son los artículos que publicó el médico de San Fernando (Cádiz), José Ignacio Cellier Ortega, en las páginas de la revista que dirigía en las primeras décadas del siglo XX, "La Medicina Práctica", revista sobre la que realizaron un estudio monográfico Olagüe de Ros y Paredes Salido (1983). Cellier falleció en 1915 y se ha señalado sobre su obra médica, entre otros aspectos los siguientes, apuntes que sin duda resaltan su labor médico-sanitaria (Orozco Acuaviva, 1981):

"Destacado médico isleño, natural de San Fernando, en donde desarrolló una importante labor sanitaria como médico del Lazareto en la invasión colérica de 1885. Al conferírsele el 13 de abril de 1892 la subdelegación médica isleña dio un gran impulso a la sanidad municipal, a la que ofreció su "Gabinete Histoquímico" particular, orientado a la práctica de análisis alimenticios. Dirigió y publicó La Medicina Práctica, (...), desde el 15 de marzo de 1902, hasta su fallecimiento en 1915".

Además, Cellier, publicó obras sobre la nutrición (1896), la higiene ante el mefitismo (1896) y también trabajos sobre la higiene de la alimentación (1898-1901). También publicó Cellier, como decimos, varios artículos en esta revista sobre el particular: "Tifus exantemático. Su historia, etiología y profilaxis" (1909a); "Concepto clínico del tifus exantemático" (1909 b); "Tratamiento del tifus exantemático" (1909c). Cellier insiste en que en la mayoría de las denominaciones y conceptos tradicionales se estudia el tifus confundido con otros estados febriles de caracteres infecto-contagiosos y epidémicos, especialmente con la fiebre tifoidea, hasta que Sydenham y más adelante Hildebrand y Frank expusieron sus dudas sobre la identidad de ambos procesos, y ya a principios del siglo XIX aparecieron verdaderos cuadros y diagnósticos diferenciales, que empezaron a merecer el concepto de que el tifus y la fiebre tifoidea eran procesos completamente distintos, $\mathrm{y}$ más especialmente desde los trabajos del inglés Jenner en 1850 y del alemán Grieceinger en 1857. No se olvide que Hildebrans, en Alemania, hizo una clara distinción entre el tifus exantemático y la fiebre nerviosa o tifus abdominal, diferenciación que continuó con Perry en 1836, además Barlow, en 1840, publicó en la revista Lancet un artículo en el que calificaba a las dos enfermedades como distintas y señalaba sus diferencias clínicas, también se deben tener en cuenta los estudios anatomopatológicos de Louis (1841) (Maradona Hidalgo, 2010).

Sobre la etiología, Cellier Ortega señala que (1909a):

“...los bacilos y coli-bacilos encontrados, hasta ahora, en las múltiples investigaciones 
Cultura de los Cuidados

llevadas á cabo y que continúan efectuándose, no han llegado a determinar una individualidad distinta y especial con caracteres propios, como bacilo productor del tifus exantemático y por tanto mucho menos á diferenciarlo del bacilo de Klebs y de Eberth; pero en realidad tanto clínicamente como por la ausencia de los bacilos de la fiebre tifoidea, quedan bien deslindados ambos procesos febriles infectos contagiosos, ...".

Cellier apunta que el tifus exantemático es un proceso febril infecto-contagioso de carácter epidémico, que puede presentarse donde quiera que haya aglomeración de individuos dentro de deficientes condiciones higiénicas “...y máxime, si á tales condiciones van unidas las deficiencias fisiológicas y orgánicas y las depresiones de ánimos, y por eso se le ve en la historia de sus apariciones seguir las huellas de los ejércitos en las guerras y presentarse donde quiera que éstos han detenido sus marchas, como donde quiera que las diversas empresas humanas han tenido necesidad de reunir masas de individuos, en malas condiciones de higiene y salubridad" (Cellier Ortega, 1909a).

En este artículo Cellier hace hincapié en el desconocimiento del agente etiológico del tifus exantemático, aunque insiste en los trabajos que sobre el particular realizan los doctores Pittaluga e Illera, y en que esta epidemia en 1909 presenta "pequeños focos" en Madrid y en Sevilla (Cellier Ortega, 1909a). Asimismo, a pesar del desconocimiento etiológico, el médico de
San Fernando (Cádiz), José Ignacio Cellier Ortega, realiza un esfuerzo notable de diferenciación clínica del tifus exantemático con la fiebre tifoidea, insistiendo en los puntos "en que discrepan estos dos procesos y sus mas esenciales diferencias, á nuestro entender, mas que suficiente para marcar bien y dejar bien sentado que el tifus exantemático y la fiebre tifoidea son dos procesos completamente distintos". No solo esto, sino que también aboga por la separación indiscutible de los paratifus, colitifus y demás modalidades tíficas (Cellier Ortega, 1909b). Por todo esto, Cellier, piensa que mientras no se conozca su agente etiológico, "los prácticos han de atenerse al síndrome clínico del proceso, y éste realmente coincide mucho con el de los procesos eruptivo y exantemáticos" (Cellier Ortega, 1909b). El médico de San Fernando (Cádiz), preconiza la higiene del enfermo (Cellier Ortega, 1909c):

"El local no pecará nunca por amplio y ventilado, cuidando de sostener constantemente, si bien de forma prudencial y adecuada, su ventilación (...). Las ropas de las camas, como las del enfermo, deben estar muy bien desinfectadas y ser remudadas todo lo más frecuente posible, para que se conserven muy limpias (...). Uno de los puntos más interesantes es el aseo corporal del enfermo, empleando ya baños de agua sola ó bien de agua jabonosa con jabón verde ó del llamado de lavar, sin que lo exijan la marcha sintomática del proceso, sino solo y excesivamente como medio necesario y muy útil de aseo corporal". 
Revista científica de la Asociación de Historia y Antropología de los Cuidados (Universidad de Alicante)

Recordemos que estos escritos de Cellier

Ortega datan de 1909, cuando en Madrid y Sevilla, por ejemplo, preocupaba mucho la enfermedad, lo que justifica los esfuerzos del médico gaditano por hacer una revisión clínica, etiológica y preventiva, según los conocimientos de la época; sobre su figura, sobre sus publicaciones, y sobre estos y otros trabajos publicados en "La Medicina Práctica", o sus monografías, insistiremos en futuros trabajos. Sobre el tifus exantemático en Madrid a principios del siglo XX recomendamos el estudio en profundidad del excelente trabajo de Santiago de Miguel Salanova (2017).

En lo que se refiere a los estudios del agente causante del tifus exantemático ha realizado una buena síntesis Maradona Hidalgo (2010), señalando como estas investigaciones les costó la vida a algunos de los protagonistas:

"Los primeros fueron el patólogo estadounidense Howard Taylor Ricketts (1871-1910), (..) y su ayudante Russel Wilder. Ambos viajaron a México para investigar sobre esta infección y allí descubrieron el microorganismo responsable, tanto en los piojos (Pediculus corporis), que lo albergan y vehiculan de persona a persona, como en la sangre de los propios enfermos, pero no pudieron cultivarlo. Siguieron entre 1913 y 1914 las investigaciones del zoólogo y parasitólogo austriaco Stanislaus von Prowazek (18751915), que efectuó muchas observaciones sobre la enfermedad, el parásito y la bacteria causante. En 1915 Prowazek y el investigador brasileño Henrique da Rocha Lima (1879-1956) fueron comisionados para investigar una epidemia de tifus en prisioneros en un campo cerca de Brandemburgo. Ambos contrajeron la enfermedad a la vez, pero mientras Da Rocha Lima se recuperaba y aislaba el agente causante, Prowazek murió. Da Rocha Lima llamó a la bacteria Rickettsia prowazekii en honor de Prowazek y de Ricketts, que también había muerto de esta enfermedad mientras la estudiaba".

No se deben olvidar los estudios de Nicolle, Comte y Conseil, que en el Laboratorio del Instituto Pasteur de Túnez, transmitieron la enfermedad a monos en cuya piel se habían colocado piojos infectados. Igualmente merecen ser recordados los estudios de Wilden, Gavino, Girad, Anderson y Goldberger (García del Real, 1933). Recuérdese que Rodríguez Ocaña ha cuestionado el papel de Carlos María Cortezo Prieto (1850-1933), en ciertos aspectos de la investigación sobre el tifus exantemático (2007): "En mi opinión, la adjudicación a Cortezo de la prioridad en relación con la transmisión del tifus es una presunción infundada, que no sostienen ni las fuentes de 1903, ni la voz de Cortezo, ni la práctica sanitaria española anterior a 1910".

Sobre el diagnóstico diferencial del tifus exantemático hemos insistido en otro trabajo, a partir de una Circular, firmada en Cádiz, en mayo de 1940, en la cual se insiste 
en el período de incubación, en el periodo de invasión y el periodo de estado (HerreraRodríguez, 1997). En este documento emitido por la Sección de Epidemiología "del Instituto Provincial de Sanidad" (sic), se expone resumidamente que el período de incubación es de 5 a 20 días, y que el período de invasión dura 4 ó 5 días, cursando con escalofríos, fiebre $\left(40-41^{\circ}\right)$, cefalalgia frontal, raquialgia, sed intensa, náuseas, puede haber vómitos, angina eritematosa y conjuntivitis, catarro de las vías altas, epistaxis y el signo de la lengua. En cuanto al período de estado queda parcelado en un primer septenario y un segundo septenario. En el primero el paciente tiene estupor y el exantema presenta unas características: pequeñas manchas, de forma irregular, color rosa pálido, primero a los lados del vientre y en los pliegues de los miembros, generalizándose a todo el cuerpo, con excepción de cuello y cara, también manchas mayores de 1 ó 2 centímetros. En el segundo septenario, la temperatura sigue elevada, las bases del pulmón se congestionan y la respiración se hace anhelante, puede haber estreñimiento y retención de orina, y la piel seca y ardiente tiene tendencia a formarse escaras por decúbito. Al final de este segundo septenario el exantema comienza, por lo común, a borrarse. En esta Circular se avisa de los posibles casos "indiagnosticados":

"Debe tenerse en cuenta a este respecto, que pueden presentarse casos de esta última enfermedad (tifus exantemático), que por su escasa gravedad (tiphus levisimus, de
Hildebrand) y corta duración, con exantema discreto y efímero que hasta llega a faltar en algunos casos, puede pasar indiagnosticados".

En los años 40, en nuestro país, aparecieron monografías y libros sobre los aspectos etiológicos, profilácticos, epidemiológicos y clínicos. Entre estas obras, en las cuales se hace hincapié en la sintomatología del tifus exantemático y en el diagnóstico diferencial con la fiebre tifoidea u otras enfermedades, encontramos las de G. Clavero y F. Pérez Gallardo (1941) y Primitivo de la Quintana (1942).

\section{3.- El tifus exantemático en España y en la provincia de Cádiz en la década de los 40}

Las defunciones por tifus exantemático que se contabilizaron en España, entre 1911 y 1925, fueron 1.457. Y el promedio de muertes por esta enfermedad, entre 1926 y 1930, fue de 11 (Pascua, 1934). En 1933, Eduardo García del Real, en su discurso de ingreso en la Real Academia Nacional de Medicina, avisó sobre las consecuencias dramáticas que podía provocar en el Madrid de los menesterosos la aparición del tifus exantemático (García del Real, 1933; Herrera-Rodríguez, 1997). Entre 1900 y 1935, fueron especialmente complicados, con respecto al tifus exantemático, en cuanto a defunciones, los años 1903, 1904, 1905, 1909, 1910, 1911, 1912, 1913, 1919 у 1920 (Quintana, 1942; Pascua, 1934). En lo referido a 1903, 1904, 1905, 1909, 1910 y 1913, se debe señalar que la elevación de 
Revista científica de la Asociación de Historia y Antropología de los Cuidados (Universidad de Alicante)

estos años concuerda con los aumentos acaecidos en Madrid, siendo las epidemias de la capital las que han influenciado y dado la tónica general a la curva nacional de mortalidad por tifus exantemático. Aunque esta circunstancia no se produce igualmente en los años 1919 y 1920, en que la curva de España se alza sobre la de Madrid, debiéndose en este caso a las epidemias de tifus ocurridas en las provincias de Murcia y de Granada. Como ya señalamos en otro trabajo, citando a Primitivo de la Quintana, entre 1901 y 1935, las defunciones ocurridas en Madrid por el tifus exantemático constituyen el $47,6 \%$ de las ocurridas en toda España (Quintana, 1942; HerreraRodríguez, 1997).

Se debe apuntar también que con anterioridad a la Guerra Civil, en Madrid, estaba prácticamente extinguido el foco endémico tradicional. De hecho, en la capital de España, en el periodo que abarca de 1933 a 1935, no se produjo ninguna defunción por tifus exantemático; pero a los pocos días de terminar la guerra, en el mes de abril de 1939 se notificó en Madrid el primer caso de tifus exantemático. La mayor parte de los casos producidos tienen su procedencia fuera del ámbito de la capital e incluso fuera de la provincia de Madrid, perteneciendo en su mayoría al Centro y Sudoeste de la Península, sobre todo de Murcia y Valencia, señalándose también a las provincias andaluzas de Almería y Córdoba. En esta circunstancia tuvo mucho que ver el éxodo de personas que provocó el final de la guerra (Quintana, 1942).

Según datos oficiales el tifus exantemático provocó en España, en 1941, 1.644 muertes y en 1942 se contabilizaron 1.542, según apuntan los libros del Movimiento natural de la población de esos años (Herrera-Rodríguez, 1997). En 1943 fueron 291; en 1944 murieron 117; en 1945 descendió la mortalidad a 15, y en 1946 y 1947 las cifras, respectivamente, fueron de 25 y 49 (Rodríguez Ocaña, 2017: Navarro García, 2002). En lo que se refiere a la morbilidad se apuntan los siguientes casos: en 1941: 8.699; en 1942: 8.433; en 1943: 1.134; en 1944: 547; en 1945: 58; en 1946: 220; en 1947: 250 (Rodríguez Ocaña, 2017: Navarro García, 2002). Debe apuntarse que para 1941 se apuntaron cifras de morbilidad superiores por tifus exantemático, concretamente 12.600 enfermos (Palanca, 1943; Cf. este apunte en Herrera-Rodríguez, 1997).

Centremos nuestros comentarios en la provincia de Cádiz. En 1940 no se produjeron defunciones por tifus exantemático, pero preocupación por la enfermedad sí existía en la provincia, ya que se estaban produciendo defunciones en 1940 en provincias andaluzas como Sevilla, Granada, Jaén, Córdoba o Almería, una prueba de esta preocupación es que la Sección de Epidemiología del "Instituto Provincial de Cádiz" (sic), como hemos indicado, publicó una Circular en el mes de mayo con el título de "El diagnóstico 
diferencial del tifus exantemático", en este documento se insiste en los aspectos clínicos, pero también en la posibilidad de que se propague la epidemia en la provincia gaditana (Herrera-Rodríguez, 1997).

En 1941, la Dirección General de Sanidad, mostró su preocupación por los problemas que estaba generando el tifus exantemático, ya que la enfermedad presentaba cuatro frentes geográficos: Sevilla, Granada, Málaga y Madrid; pero además se señala varios frentes secundarios en Almería, Murcia, Valencia, Jaén, Córdoba y Cádiz (Palanca, 1943; HerreraRodríguez, 1997). En 1941 nada fue equiparable a la epidemia de Málaga (Palanca, 1943), que cuenta con un excelente estudio monográfico de Jiménez Lucena (1990), y en 1942 fue la provincia de Cádiz la que más preocupaciones causó a las autoridades sanitarias (Palanca, 1943; Herrera-Rodríguez, 1997):

“...no sólo por los casos de la capital, sino por la epidemia más seria de San Fernando y la de Barbate, las dos tomando como campo de acción barrios de casas de hoja de lata, imposibles de desinsectar y de tales condiciones higiénicas que en apenas diez metros cuadrado de superficie está todo reunido, camastros cocina, dormitorios y despensa, donde la hay. El Ayuntamiento de San Fernando no anduvo muy diligente en auxiliar a los que combatían la epidemia que se prolongó durante mucho tiempo; pero no procedió lo mismo el Alcalde de Barbate, que con toda celeridad hizo otro cordón sanitario alrededor de las chozas, y lo que fracasó en Villarrobledo triunfó aquí por la acción de una autoridad celosa y decidida a terminar con el peligro".

Las localidades de San Fernando y Barbate, requieren de estudios monográficos específicos, como se hizo en lo referido a Cádiz capital, motivo por el que no insistiremos sobre datos particulares de estas dos localidades de la provincia gaditana y centraremos nuestros esfuerzos en exponer nuestras indagaciones sobre el particular, refiriéndonos a la ciudad de Jerez de la Frontera, no sin antes apuntar algunos datos sobre los responsables de la Jefatura Provincial de Sanidad de Cádiz.

Sabemos sobre este asunto que la Jefatura Provincial de Sanidad de Cádiz tenía su sede en la gaditana "calle Beato Diego de Cádiz" (entrada por la calle Manuel Rancés) y que en noviembre de 1941 tomó posesión de este cargo Adolfo Vila, que venía desempeñando el puesto de forma intermitente, y sobre el que hemos aportado datos en otro estudio (Herrera-Rodríguez, 2019). De hecho podemos aportar documentación firmada por Adolfo Vila como Jefe Provincial de Sanidad, una Circular firmada el 5 de febrero de 1940 y otro firmado con fecha 4 de marzo de 1941 (Protocolo Municipal 663-1940, AMJF; Protocolo Municipal 718-1941, AMJF). En febrero de 1942 es Donato Fuejo García el que firma como responsable de este cargo las disposiciones para combatir el tifus exantemático (Herrera-Rodríguez, 1997) (figura 1). 
Figura 1: Donato Fuejo García (Jefe Provincial de Sanidad de Cádiz)

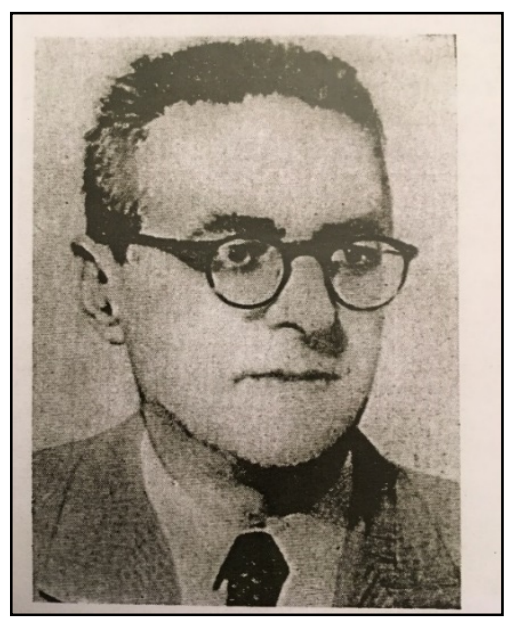

Fuente: Herrera-Rodríguez, 2001.

Sobre este médico debemos hacer referencia a su "Informe sobre la epidemia de Tifus Exantemático en la provincia, que presenta el Jefe de Sanidad Dr. D. Donato Fuejo", cuya referencia incluimos en fuentes documentales (Fuejo, [1943]) (figura 2). Recuérdense varios problemas que señaló Fuejo en este Informe epidemiológico. Dice así:

"Para hacer frente al problema, la primer dificultad que se me presentaba era mi desconocimiento de las características de la provincia y aun de la región, puesto que mi ejercicio profesional se había desenvuelto siempre en las provincias del Norte. Una segunda dificultad la constituía la falta de información, que, por razones diversas y muy importante a tener en cuenta para los servicios no me fue facilitada con los detalles necesarios. En tercer lugar, la organización sanitaria provincial carecía de instrumentos para luchar contra el tifus exantemático".

Ténganse, en cuenta, estos comentarios de Donato Fuejo sobre la falta de información, que no le fue facilitada con "los detalles necesarios". Sobre este particular de la información epidemiólogica y de mortalidad, insistiremos en el Epílogo de nuestro trabajo. Hay momentos en su Informe, sobre todo, en lo referido a la ciudad de San Fernando en los que afirma “...pasamos un verdadero calvario".

No es de extrañar que Donato Fuejo estuviera abrumado nada más llegar al cargo, encontrándose con una epidemia de tifus exantemático, y no sería ésta su única tarea, sino muchas otras también, en lo referido a control, organización, vigilancia sanitaria, etc. Recuérdese que una Orden de 30 de septiembre de 1939, aparecida en BOE de 2 de octubre, reorganizó las Jefaturas provinciales de Sanidad, nombre con que se designó a las antiguas Inspecciones provinciales de Sanidad. Entre los servicios de las Jefaturas provinciales de Sanidad se encuentran los servicios sanitarios, higiénico-sanitarios y sanitarios sociales, entre los que destacan la Sanidad Exterior, en las provincias marítimas; la epidemiología, vacunaciones, desinfección, estadística e higiene del trabajo; análisis higiénico-sanitario; tuberculosis, adscritos al Patronato Nacional Antituberculoso; Puericultura y Maternología e Higiene escolar; Venereología, lepra y enfermedades parasitarias de la piel; Paludismo, 
anquilostomiasis y Kala-azar; Ingeniería y

Arquitectura sanitaria, higiene $\mathrm{y}$ saneamiento urbano y rural, obras sanitarias; Higiene de la alimentación y vigilancia de alimentos y bebidas; Cáncer y radiumterapia; Higiene mental y toxicomanías; Oftalmología; Otorrinolaringología; Odontología. Además de los servicios llamados parasanitarios y profesionales, que comprenden la Medicina Social, antiguas Comisarías Sanitarias; Médicos de Asistencia Pública Domiciliaria y profesiones auxiliares, oficiales y libres (practicantes, matronas, enfermeras); farmacéuticos titulares y libres (Cf. estas tareas con más detalle en "Servicios Centrales de Higiene Infantil. Disposiciones Sanitarias dictadas durante los años 1939 y 1940...", 1941, Archivo FHR). Una vez aclarado este punto, volvamos al Informe de Donato Fuejo sobre esta epidemia de tifus exantemático en la provincia de Cádiz.

Figura 2: Informe del Jefe Provincial de Sanidad de Cádiz, Donato Fuejo, sobre el tifus exantemático en la provincia de Cádiz

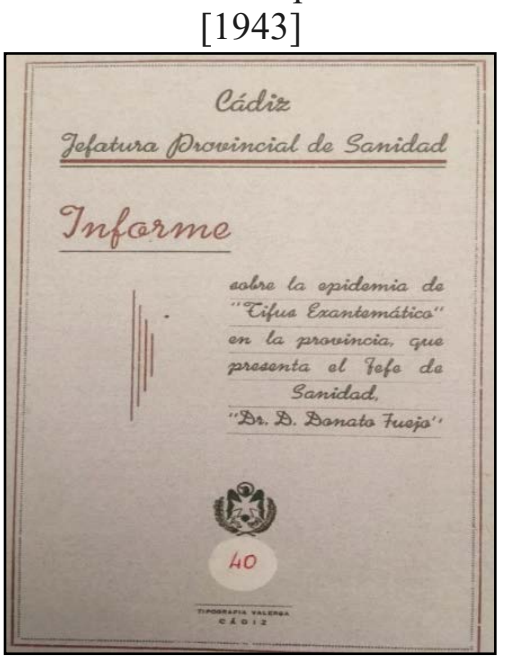

Fuente: Biblioteca de Andalucía. Sucursal: Biblioteca de Andalucía (Granada).
En esta monografía, Donato Fuejo, confirma como apuntamos, que accedió a la Jefatura Provincial de Cádiz en febrero de 1942, apuntando lo siguiente:

"En el mes de Febrero de 1942, fecha de mi llegada a esta Jefatura, había sufrido la provincia en el año 41 y Enero del 42 los efectos de la presencia del tifus exantemático y en proporciones considerables. Figuran declarados en este lapso de tiempo 742 casos y 97 defunciones, y se había presentado la enfermedad en 17 de los principales Ayuntamientos de la provincia, y en ese instante San Fernando estaba sufriendo un intenso brote epidémico, pues en el mes de Enero se habían presentado 118 casos y 9 defunciones; el Ayuntamiento de Puerto Real tenía con el tifus exantemático un grave problema, pues se declararon en este mes 48 casos y 7 defunciones, y con estos dos, la capital, que también presentaba 11 casos, constituían para mí la más importante preocupación sanitaria".

Este Informe de Donato Fuejo debe ser estudiado monográficamente, con mucha atención, ya que está lleno de matices, sobre todo cuando se recopile información de morbilidad y mortalidad en documentación sanitaria y libros de registro civil de defunciones de los municipios de la provincia de Cádiz, pero también información sobre el medio carcelario y lugares de aislamiento en la provincia de Cádiz. Fuejo apunta lo siguiente: 
Revista científica de la Asociación de Historia y Antropología de los Cuidados (Universidad de Alicante)

"Debemos considerar el conjunto de casos ocurridos de tifus exantemático durante el año 1941 y 1942, como una sola epidemia con dos exacerbaciones y una pausa intermedia. Los primeros casos aparecen declarados en Abril de 1941 en Algeciras, pero en el mes siguiente ya se declaran en la capital, en Jerez de la Frontera, en San Roque, en Puerto Real y en la Línea de la Concepción. Los de Algeciras y Jerez de la Frontera, fueron 79 y 194 respectivamente (...). La curvación epidémica del año 41, de la curva general de casos de tifus exantemático, está formada casi totalmente por la suma del brote de Jerez de la Frontera y Algeciras, hasta que en el mes de Julio aparecen en la capital declarados 80 casos, sumando un total de 200 los declarados en la misma. La explicación de esta explosión epidémica en la capital no es tan clara como en las dos localidades anteriores, pues no aparecen afectados centros o aglomeraciones cerradas y solamente aparecen declarados dos casos en Mayo y cinco en Junio".

Hay que tener en cuenta, sobre los datos apuntados, que hemos constatado que la primera defunción por tifus exantemático que consta en el Registro Civil de la ciudad de Cádiz data del mes de febrero de 1941 (Herrera-Rodríguez, 1997), lo que no quiere decir, como bien ha precisado Jiménez Lucena para Málaga, que no se produjeran defunciones con anterioridad a esta fecha, sobre todo teniendo en cuenta la dificultad de establecer el diagnóstico diferencial con otras patologías como la gripe o la fiebre tifoidea, o que se apuntara en los libros de registros de defunciones la bronconeumonía, que podía presentarse como una complicación en el curso de la enfermedad (Jiménez Lucena, 1990).

\section{4.- El tifus exantemático en Jerez de la Frontera (1941-1942)}

Para trazar una panorámica del problema del tifus exantemático en Jerez de la Frontera, en los años señalados, hemos recurrido a diversas fuentes documentales, entre las que debemos destacar la monografía citada de Donato Fuejo; los trabajos del Director del Laboratorio Municipal de Higiene de Jerez en esos años, José Estrade Camúñez (1904-1973) (figura 3), sobre cuya figura estamos trabajando para una futura publicación, contando en la actualidad con la síntesis biográfica realizada por su hijo Manuel S. Estrade Pando (2017); también hemos utilizado el periódico jerezano “Ayer”, así como diversa documentación administrativa que se conserva en el Archivo Municipal de Jerez de la Frontera, todo este material lo iremos citando a medida que avancemos en la narración de lo acontecido en esta localidad en lo referido al tifus exantemático.

Donato Fuejo en la tabla que presenta en su monografía, referida al año 1941, sobre el tifus exantemático, con información de 16 poblaciones de la provincia de Cádiz, apunta 609 casos y 86 defunciones. Matizando que 
en Cádiz capital se produjeron 209 casos y 29 defunciones, y en Jerez de la Frontera 194 casos y 24 defunciones (tabla 5). En cambio, Estrade Camúñez señala en su Memoria referida a Jerez, correspondiente al año 1941, 162 casos de tifus exantemático.

Y en 1942, Donato Fuejo, con información de 15 poblaciones de la provincia, señala la cifra de 1.319 casos y 152 defunciones, apuntando para Cádiz capital 147 casos y 18 defunciones; para Jerez de la Frontera, 25 casos y 2 defunciones (tabla 6), sobresaliendo en 1942 los casos y defunciones en las localidades de la provincia gaditana de San Fernando, Puerto Real y Barbate (Fuejo, [1943]). Se debe apuntar que Estrade Camúñez, en su Memoria correspondiente al año 1942, apunta 19 casos de tifus exantemático en Jerez de la Frontera, frente a los 25 casos que hemos señalado que apuntó Fuejo. Sobre Cádiz capital véase el estudio de HerreraRodríguez (1997). Sobre esta cuestión insistiremos en el "Epílogo" de este artículo, con algunas reflexiones sobre la información de diversas fuentes documentales, los datos ofrecidos por los libros de movimiento natural de la población referidos a la provincia de Cádiz en 1941 y 1942 y las tasas de mortalidad específica.

José Estrade Camúñez, director del Laboratorio Municipal de Higiene de Jerez de la Frontera (figura 3), como hemos citado anteriormente, realizaba una Memoria anual con las actividades del laboratorio, en los que solía incluir datos de morbilidad y de mortalidad de la localidad jerezana (Cf. las citadas Memorias en el capítulo de Fuentes y véase al respecto la tabla 2 que presentamos en este artículo que incluye tasas de mortalidad general de Jerez del periodo de la guerra civil y de los años 40). Normalmente estas Memorias las editaba el Ayuntamiento, pero algunas de ellas como la referida a las actividades del Laboratorio Municipal de Higiene realizadas durante el año 1959 no nos consta que fuera publicada, pero sí existe un ejemplar mecanografiado en el que comprobamos que fue redactada por José Estrade. Estas Memorias se encuentran en el Archivo Municipal de Jerez de la Frontera, gracias a la donación que a esta institución realizó su hijo, Manuel S. Estrade Pando.

En la Memoria de las actividades del citado Laboratorio, realizadas durante el año 1959, José Estrade Camúñez, expone un informe sobre las enfermedades que han afectado o afectan a Jerez, incluyendo algunas páginas sobre la epidemia de tifus exantemático en la localidad en los años 1941 y 1942 (Estrade [1959]). Estrade afirma que "nunca se habia registrado en esta población ningún caso de tifus exantemático", afirmación que no fundamenta con datos precisos. Sí nos parece de gran interés para entender cómo evolucionó la epidemia en Jerez los datos más precisos que ofrece; por ejemplo, que de la epidemia se hizo cargo el Jefe de los Servicios Sanitarios de Jerez, Salvador 
Revista científica de la Asociación de Historia y Antropología de los Cuidados (Universidad de Alicante)

Dastis, con la cooperación del propio

Estrade y del Laboratorio que dirigía, "con los servicios de la Dirección, la Jefatura de Epidemiología y los empleados de desinfección" (Estrade [1959]). Obviamente tendrían muy en cuenta las directrices de la Jefatura Provincial de Sanidad, que desde febrero de 1942 tenía como responsable, como hemos indicado, a Donato Fuejo García.

Figura 3: José Estrade Camúñez (19041973)

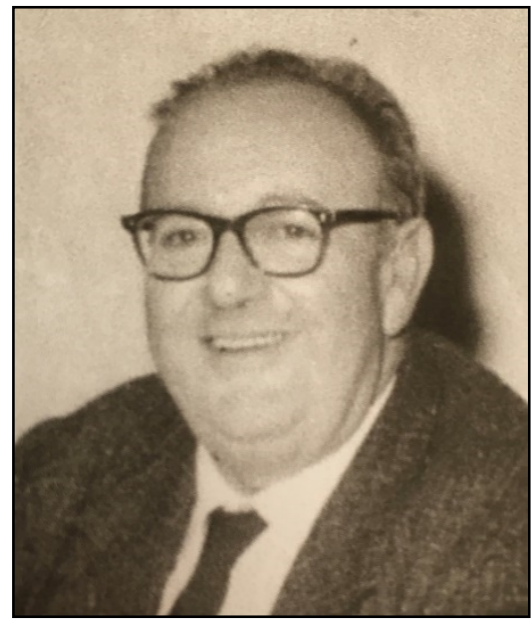

Fuente: Estrade Pando (2017)

José Estrade apunta que fue a finales del mes de mayo de 1941 cuando surgió el brote epidémico, hecho en el que coincide con lo que apunta el Jefe Provincial de Sanidad. Fuejo señala 53 casos y 3 defunciones en el mes de mayo (tabla 5). Estrade sostiene que "por las investigaciones epidemiológicas que se hicieron se descubrió que habian sido importados de Sevilla y de Algeciras", aunque apunta que este brote fue de 43 casos, teniendo "graves caracteres por la masividad y extensión que adquirió desde los primeros momentos" (Estrade [1959]). De hecho, como hemos apuntado, y puede verse en las tablas 5 y 6 , en 1941 se contabilizaron 194 casos y 24 defunciones, y en 1942, 25 casos y 2 defunciones. Una matización más sobre los primeros casos en la provincia de Cádiz; al parecer, según apunta Donato Fuejo [1943], los primeros casos aparecen declarados en abril de 1941 en Algeciras, y como ya hemos visto en mayo ya se declararon casos en Jerez de la Frontera, Cádiz, San Roque, Puerto Real y la Línea de la Concepción (Fuejo, [1943]). Aunque, como hemos apuntado, en Cádiz capital hemos localizado 1 defunción ocasionada por el tifus exantemático en febrero de 1941 (Herrera-Rodríguez, 1997).

El 21 de mayo de 1941, se lleva a cabo una denuncia a la Alcaldía de Jerez de la Frontera, en la que consta que en la calle Alcaidesa $n^{0} 11$ se encuentra una enferma en cama, con fiebre y cubierta de piojos, que se niega a recibir asistencia médica. Hemos encontrado documentación del servicio de ambulancias, fechada el 31 de mayo de 1941, en la que se da cuenta del traslado de 131 indigentes y de 66 enfermos contagiosos de tifus. Hay que 
tener en cuenta también que en el mes de abril el Gobernador Civil de la provincia, Manuel Mora-Figueroa, y el Alcalde de Jerez, José de MoraFigueroa, firman un Bando en el que se prohíbe la limosna en vía pública, señalando que toda persona que ejerza la mendicidad será detenida (Protocolo Municipal 718-1941, AMJF).

Hemos querido profundizar en lo referido a las defunciones producidas en Jerez por el tifus exantemático, que según los datos que hemos apuntado sumarían un total de 26 , concretamente 24 en 1941 y 2 en 1942, para ello hemos recurrido a los libros de Cementerio, más concretamente a los libros de justificantes de enterramientos de esos años que se encuentran depositados en el Archivo Municipal de Jerez de la Frontera (Cf. Cementerio. Justificantes de enterramiento: del 448 al 455 y 458 459; Libro Cementerio 138).

Del total de los 26 fallecimientos por esta enfermedad en Jerez de la Frontera, que se ha apuntado con anterioridad para los años 1941 y 1942, hemos encontrado noticias específicas en la citada documentación de 23; de los cuales, 14 hombres y 9 mujeres. Diez estaban casados, 4 solteras, 3 viudas, 2 religiosas y en 4 casos no consta este dato. En estas fuentes documentales hemos comprobado que los diagnósticos en los que consta el tifus exantemático como causa de

muerte aparece con diferentes denominaciones: "tifus exantemático" (6), "sospechoso de tifus exantemático" (2), "tifus exantemático epidémico" (11), "Toxemia. Tifus exantemático epidémico" (1), "Toxemia. Tifus exantemático" (1), "Miocarditis. Tifus exantemático" (1), "Miocarditis. Tifus" (1). Debemos señalar que 1 defunción consignada como "Coma infeccioso" no la hemos incluido, correspondiente a una mujer casada, aunque probablemente también estuviera causada por el tifus exantemático, ya que falleció en el Lazareto de la Atalaya, sobre el que más adelante haremos algunos comentarios. Los médicos que firmaron los partes de defunción son los siguientes: Luis Soler Jiménez (16 partes firmados), Valentín Gavala Calderón (4 partes), Elías Durán Moya (1 parte), Juan Carlos Durán Brave (1 parte), José Matos Soto (1 parte).

En cuanto a las edades de estas 23 personas, relacionadas con el tifus exantemático en Jerez de la Frontera, observamos que 6 estaban comprendidas entre los 31 y 40 años de edad, 6 entre los 41 y 50 años, 3 entre los 56 y 65 años, 5 entre los 66 y 75 años, y en 3 casos no consta la edad.

En cuanto a profesiones $\mathrm{y}$ ocupaciones: en 4 casos consta "sus 
Revista científica de la Asociación de Historia y Antropología de los Cuidados (Universidad de Alicante)

labores o su casa", en 2 "empleados", Este apunte merece que en 3 "del campo", en 1 "chapista", en 1 "Portero Mayor del Ayuntamiento", en 2 "Religiosas", en 1 "topiquera", en 1 “albañil”, en 1 "pescadero" y en 7 "no consta" la profesión u ocupación. Donato Fuejo [1943] apunta en su informe sobre la epidemia que en Jerez de la Frontera fallecieron 4 personas "de las clases sanitarias", tributo pagado a la lucha contra el tifus exantemático, cuyos fallecimientos quedaron registrados en los libros de registro del Cementerio (Libro Cementerio 138). Consignamos sus nombres y ocupaciones:

-Sor Isabel Lluch Pastor (Hermana de San Vicente de Paúl).

-Sor María Ferrer Carrera (Hermana de San Vicente de Paul).

-Don José Miguel Ruiz Neupaver (Practicante).

-Doña Dolores Crespo Luque (Topiquera).

Sobre el lazareto de la Atalaya consignamos que en el mismo fallecieron 17 de las 23 personas estudiadas; 2 murieron en el Hospital de la Casa Cuna, 1 en un domicilio de la calle Dr. Ruiz de la Rabia, 1 en el Hospital y en 2 casos se apunta el fallecimiento en la "calle del Hospital".

dediquemos atención a los lugares en que se prestó asistencia en Jerez en la lucha contra el tifus exantemático. Sabemos por Estrade Camúñez que se crearon dos centros de aislamiento la ciudad: uno en la finca La Atalaya y el otro en la antigua Casa Cuna para los presos de la prisión Central, también se organizó "un campo para concentración de mendigos en el Balneario de San Telmo, investigación de casos sospechosos y diagnóstico bacteriológico de los enfermos y por último hospitalización forzosa de los que no reunian [en] sus domicilios las condiciones higiénicas" (Estrade [1959]).

Hemos encontrado un expediente que data de 1942 y lleva por título "Construcción de unos barracones de aislamiento de mendigos" (Cf. Legajo 1.174, Expediente 24.845, AMJF). Comprobamos que en enero de 1942 se plantea la necesidad de construir tres barracones de madera en el Balneario de San Telmo, "con destino al aislamiento y recogida de mendigos de Esta ciudad, por carecerse de local adecuado a dicho objeto, interesaron del Sr. Arquitecto Municipal la confección del oportuno proyecto facultativo y presupuesto ascendente a pesetas 67.500”. Cada uno de estos barracones tendría el coste de 22.500 
Cultura de los Cuidados

pesetas. Todo esto se plantea "en

previsión de que se reproduzca la pasada Epidemia de tifus Exantemático". A finales de mayo de 1942 la Jefatura Provincial de Sanidad comunica al Alcalde de Jerez que la propuesta ha sido informada favorablemente, pero "por un importe de 27.424,43 pesetas". En septiembre de 1942 se comunica a la Jefatura Provincial de Sanidad la cuenta de 27.397 pesetas, “importe de la construcción por Administración de un barracón de aislamiento de mendigos, en esta Ciudad, en el sitio denominado Balneario de San Telmo".

Sobre la Prisión del Partido señala lo siguiente (Estrade [1959]):

“...la carencia de condiciones higiénicas de la misma y la ausencia absoluta de instalaciones sanitarias e higiénicas en el citado edificio, hizo necesaria la adopción de medidas excepcionales, para terminar con aquel brote epidémico; montaje de un sistema de duchas y de baños, algo primitivos, pero de indudable buen resultado; construcción de cámara de gases, para desinsectaciones urgentes; despiojamiento total y absoluto de toda la población penal y traslado de la misma a un local previamente habilitado para Prisión por V.E., dotando a los presos de ropa nueva, mientras en nuestros servicios se desinsectaban las de uso diario de todo el personal; las que recibian de sus familiares y las que salian de dicho establecimiento penitenciario, con destino a los distintos puntos de España, en donde residian los familiares de los reclusos. Los reclusos afectos de tifus pasaban al edificio de la Casa Cuna, en donde se les habilitó un Hospital de Infeccioso y en donde también se les montó cámara de gases y demás servicios de carácter urgente (...). Quedando resuelta la epidemia sin que se haya dado caso alguno hasta el dia de hoy".

Sobre esta última afirmación, recuérdese que la Memoria de José Estrade Camúñez que nos surte de la información que transcribimos corresponde al año 1959, en la cual ofrece una recapitulación sobre la epidemia de tifus exantemático en Jerez en 1941 y 1942. A todo esto debe añadirse que con fecha 22 de agosto de 1941 desde el Distrito Sanitario de Jerez se le comunicó al Alcalde los problemas que en el mes de mayo existieron en la Prisión del Partido, como consecuencia de una petición de informe del Juzgado. Dice así (Protocolo Municipal 730, AMJF):

"En contestación a su atento oficio del 12 del corriente, tengo el honor de manifestar a V.S. que el 24 de Mayo ppdo. Al tener conocimiento de existir 
Revista científica de la Asociación de Historia y Antropología de los Cuidados (Universidad de Alicante)

en la Prisión del Partido de ésta Ciudad unos casos sospechosos de tifus exantemáticos, y giré a dicho Establecimiento una detenida visita de Inspección, para la que se me dio toda clase de facilidades por el personal del mismo. En dicha me acompañó el Médico Forense D. Sebastián Guerrero. La impresión que me causó esta visita fue penosa al comprobar la existencia de varios reclusos atacados de tifus, y comprender que dadas las pésimas condiciones del local y el hacinamiento en que convivían los reclusos era humanamente imposible impedir el contagio a los demás y por ello propuse a la Alcaldía gestionara la evacuación completa del edificio aparte de otras medidas de carácter sanitario elementales en todo Establecimiento en el que conviven numerosas personas y que observé no se cumplian, referentes a la limpieza del local, separación y aislamiento de enfermos contagiosos, prohibición de entrada y salida de ropas, cestos y útiles de trabajo y labores confeccionadas incluso por atacados de sarna. Según me informó el Forense Sr. Guerrero él se había quejado varias veces al Director: de éstas deficiencias, y por escrito el 7 de Abril había solicitado la adopción de diferentes medidas de limpieza y desinfección del local y personas pero éstas no se habian realizado. Desde el 24 de Mayo el Sr. Guerrero diariamente comunicaba a ésta inspección cuantos casos nuevos de tifus se presentaron hasta el número de 88, y cooperó en las medidas adoptadas para el trabajo de reclusos a la Plaza de Toros, con lo que se extirpó la epidemia, apreciando divergencias entre él y el personal de la Prisión con el consiguiente retardo y eficacia de las medidas sanitarias propuestas...".

En cuanto a la utilización del Hospital de Aislamiento "Atalaya", hemos localizado un documento emitido por el contable del Hospital Municipal de Santa Isabel de Jerez de la Frontera, dirigido al Alcalde de Jerez, con fecha 2 de octubre de 1942, en el que se expone que "con fecha de hoy se ha reintegrado a su cargo del enfermero de este Hospital Municipal de Sta. Isabel Don José Mella Cachedo, por haber sido cerrado el Hospital de Aislamiento “Atalaya” (...). Al mismo tiempo ruego a V.S. me ordene lo que proceda hacer con el enfermero Don Manuel Paz Puente que desde el día 2 del próximo pasado mes de agosto venía sustituyendo al antes mencionado don José Mella Cacheda” (Protocolo Municipal 730, AMJF).

Como hemos indicado, de las 26 defunciones que señala Donato Fuejo que se produjeron en Jerez de la 
Cultura de los Cuidados

Frontera hemos conseguido

información, en los libros de

Cementerio, citados en el apartado de

Fuentes documentales de este artículo, sobre 23. De estos podemos señalar que en mayo de 1941 fallecieron 3 personas; en junio, 11; en julio, 6; en agosto, 2; y, en mayo, de 1942, 1 fallecido.

Conviene que exploremos ahora las medidas sanitarias que se llevaron a cabo en Jerez de la Frontera en la lucha contra esta epidemia. José Estrade Camúñez firmó un Bando, con la autorización del alcalde José de MoraFigueroa, en el mes de junio de 1941, que consta de una introducción, un apartado de cómo se propaga la enfermedad y otro dedicado a los "medios para prevenirse del contagio". Estrade define el tifus exantemático como una enfermedad infecciosa $y$ contagiosa, febril y aguda de carácter grave, cuyo agente causal, es el microorganismo denominado "Rickettsia prowazeki", reconociéndose como único agente transmisor, o de propagación, el piojo común, parásito de la especie humana, que cuando está infectado contiene el germen en el interior de su tubo digestivo. Sobre este parásito se extiende Estrade en este Bando, con el que pretende hacer divulgación de conocimientos sanitarios y de higiene.
Dice así (Estrade Camúñez, Bando, 1941):

"El tifus exantemático lo contrae la especie humana por contagio estando perfectamente demostrado que el (...) medio de propagación es el piojo de cuerpo (pediculus vestimenti) aunque se dan casos de transmisión por los piojos de la cabeza (pediculus capitis) y nunca por los demás insectos parásitos.

El contagio del hombre enfermo al sano, solo es posible por la intervención de los piojos, por lo que puede decirse que el enfermo despiojado deja de ser peligroso para los demás en tanto se mantengan en estado de limpieza parasitaria, precisando su aislamiento en evitación de ser parasitado nuevamente.

El pediculus capitis vive exclusivamente sobre el cuero cabelludo y muy rara vez en las axilas $y$ pubis; es de color gris con los segmentos abdominales negros en sus extremos. Deposita los huevos (liendres) y los fija sobre la base de los cabellos adheridos a una vaina de quitina, materia que también envuelve y protege a la larva. El animal sale del huevo levantando un opérculo o tapaderita que cierra su zona más abultada. El pediculus vestimenti es algo mayor que la anterior especie y de color blanco sucio. Las hembras ponen sus huevos sobre las fibras de los 
Revista científica de la Asociación de Historia y Antropología de los Cuidados (Universidad de Alicante)

vestidos entre los pliegues y costuras de los mismos. Estos piojos no suelen encontrarse sobre la piel más que cuando van a chupar la sangre, siendo muy voraces hasta el punto de realizar dos o tres succiones diarias de unos diez minutos de duración. Se reproducen en mayor abundancia que los de cabeza, siendo tan prolíficos que una sola hembra puede producir en condiciones $\quad 1.500$ descendientes en seis semanas.

Si un piojo sano pica y succiona sangre de un enfermo febril de tifus exantemático, se hace contagioso en plazo que oscila entre los 4 y 7 días desde la picadura, y sigue contagiando durante mucho tiempo y a veces toda su vida a cuantos individuos produce su picadura, porque el piojo ha contraido una enfermedad bastante duradera de la que casi nunca muere.

Los huevos de los piojos, conocidos con el nombre de liendres, cuando proceden de hembras también adquieren la infección y la conservan al nacer convirtiéndose en nuevos transmisores de la enfermedad.

El contagio se establece al chupar los piojos infectados la sangre de las personas parasitadas, operación en que como dijimos invierte a veces hasta diez minutos; tiempo sobrada para que el insecto vomite el contenido de su estómago y produzca deyecciones, $y$ como estos productos están muy contaminados y el prurito que produce la picadura es muy intenso obliga al individuo atacado a rascarse con fruición aplastando el parásito y produciéndose erosiones por las que también se establece con la frotación otra puerta de entrada de los gérmenes responsables de esta enfermedad".

En cuanto a las medidas preventivas para evitar el contagio, José Estrade Camúñez dedica un apartado extenso en el Bando, que por su claridad también preferimos transcribir:

"Las medidas generales para evitar las enfermedades infecto-contagiosas son la Vacunación Profilaxis y Desinfección.

En el caso particular del tifus exantemático sólo disponemos actualmente de medidas profilácticas, pues la vacunación preventiva es hoy tema de estudio en los Centros de investigación, y en tanto no ofrezcan las seguridades y garantía deseadas no puede hacerse su recomendación. Se ignoran los resultados obtenidos con anterioridad en otros países en sus tentativas de aplicación de vacunas preventivas en las epidemias del año 1920.

En cuanto a la desinfección propiamente dicha, podemos afirmar que se hace innecesaria porque el germen de la infección no pulula en el 
Cultura de los Cuidados

ambiente, sino en el estómago e

intestinos de los piojos infectados.

Por cuanto es la profilaxis la única medida sanitaria que podemos aplicar, a ésta deberemos dirigir todos nuestros esfuerzos. Esta medida sanitaria que podemos aplicar, a ésta deberemos dirigir todos nuestros esfuerzos. Esta medida sanitaria se condensa en la frase del profesor Salvat "Guerra al piojo”.

El empleo de sustancias como la naftalina, alcanfor $y$ otras que introducidas en bolsitas y colgadas a modo de escapularios llevan algunas personas, son de una eficacia muy dudosa como medio de alejar y evitar la invasión de los piojos. Es preferible y más seguro no confiar demasiado en estos medios abandonando lo verdaderamente eficaz, o sea, un aseo personal llevado hasta la exageración durante el tiempo de epidemia, reconociendo frecuentemente los vestidos y duchándose diariamente con jabonadura previa, pues bien sabido es, que el piojo tiene especial predilección por las gentes sucias.

La práctica de despiojamiento de las personas parasitadas es lo que puede terminar con una epidemia de esta clase. El despiojamiento se practica desnudando al sujeto parasitado $y$ aplicándole sobre el vientre y riñones dos grandes compresas mojadas en bencina o petróleo y envolviéndole con una sábana para evitar la diseminación de los parásitos que quedan así adormecidos. A continuación se pela la cabeza a rape y se le afeitan las barbas, después un gran enjabonamiento $y$ baño o ducha prolongada. Si el parasitismo es muy abundante conviene hacer desaparecer el vello de las axilas y todas las regiones pilosas del cuerpo con una pasta depilatoria aplicándose después una pomada de mercurio de calomelanos con xilol.

El despiojamiento aplicable a las mujeres cuando se quiere que conserven los cabellos, no se consigue totalmente sino en varias sesiones con aplicaciones de xilol o bencina en una compresa que envuelva los cabellos sujetando el todo con un gorro bien apretado durante una hora y peinando a continuación con un peine lendrero. Da también buen resultado el vinagre fuerte bien caliente $y$ el aceite alcanforado al 10 por 100 empleados en la misma forma.

El despiojamiento de las prendas de vestir debe practicarse tan pronto se despojan de ella los sujetos parasitados, sometiendo la ropa blanca a la ebullición por 15 minutos en agua adicionada de una pequeña cantidad de sosa. Los vestidos de lana, trajes y prendas que no se pueden hervir, se desinsectarán en una estufa de vapor a presión o también, en una cámara o 
Revista científica de la Asociación de Historia y Antropología de los Cuidados (Universidad de Alicante)

habitación herméticamente cerrada saturada de vapores sulfurosos. También se emplean con el mismo fin cámaras de aire calentado a unos 80 grados, suficiente para destruir los piojos y las liendres. Un procedimiento casero de despiojar estas prendas delicadas, es colocarlas bien estibadas sobre tenderos dentro de una habitación que cierre bien, donde se quemará azufre mezclado con alcohol y colocando la vasija de hierro u hojalata en que se practique la operación en el centro de la estancia, con las máximas precaucione para evitar un incendio. El azufre se emplea en proporción de 50 gramos por metro cúbico, debiendo actuar por lo menos seis horas los vapores para asegurar la destrucción de los piojos, y repitiendo la operación a los ocho días para matar los nuevos parásitos que nacieron de las liendres por haber éstas conservado su vitalidad en la primera operación.

Los procedimientos de despiojamiento por el empleo del gas cianhídrico son tan peligrosos que sólo están reservados a equipos sanitarios especializados con la autorización y control oficial. Estos y los que se basan en empleo del anhidrido sulfuroso son los que actualmente están más en boga para la desinsectación de locales parasitados, hospitales, lazaretos, y estancias que hayan alojado a los piojosos".
También en la prensa jerezana se dieron normas sobre el aseo personal, "hasta la exageración", como profilaxis eficaz del tifus exantemático, resumiendo el escrito de Estrade Camúñez que hemos referenciado. En este mismo periódico se anuncia "Antiparásitos Lukol", de venta en farmacia y droguerías, para eliminar los parásitos de la piel y del cuero cabelludo. Así como el "Desinfectante Luda", contra los parásitos y pulverización de locales como escuelas, hospitales, teatros, hoteles, habitaciones de enfermos, ropas, etc. (“Ayer”, 6-VI-1941).

La prensa también publicó unas instrucciones de la Alcaldía para evitar la propagación de las enfermedades epidémicas, instando a los médicos de la Beneficencia Domiciliaria a que comuniquen los casos a la Inspección Municipal de Sanidad; a los directores de las escuelas se pide que comuniquen a la Inspección la relación de los niños que no vayan a la escuela con las debidas condiciones de limpieza e higiene, así como el domicilio de los padres, también se dan instrucciones a los gerentes de empresas de transportes de viajeros, a los empresarios de espectáculos públicos y a los dueños de barberías y peluquerías. Se recuerda también que se ha habilitado un local en la Ronda de Muleros para la práctica de la desinfección y saneamiento de las 
personas desaseadas ("Ayer", 21-V1941). Se insiste en que la principal causa de la enfermedad es la suciedad de las personas, habitaciones y posadas (“Ayer”, 8-IV-1941).

También la prensa alertó de la existencia de 24 casos de tifus exantemático en New York ("Ayer", 3V-1941). Igualmente se informa de que el Gobierno ha destinado 3 millones de pesetas a la lucha contra el tifus exantemático, según declaración del Director General de Sanidad. También se escribe en la prensa jerezana las palabras del Jefe Provincial de Sanidad de Madrid, Dr. Quintana, que relacionó el origen de la epidemia con los días previos a la liberación de Madrid. Leamos: "Dijo que el primer caso se dio unos días antes de la liberación de Madrid, como consecuencia de 32 meses de suciedad. La epidemia fue atajada y durante el año 1940 no hubo caso de tifus alguno, hasta que volvió a aparecer el 4 de enero de 1941" (“Ayer", 6-IV-1941).

El 5 de abril de 1941, El Gobernador Civil, remite una carta al Alcalde de Jerez, avisando del peligro que para la salud pública significa el trasiego "de personas indigenas parasitadas", que constituyen un serio problema de albergue y alimentación, "sirvase adoptar medidas restrictivas para evitarlo denegando billetes de caridad salvo casos imprescindibles y persiguiendo la circulación de vagos, mendigos, gitanos, y otras gentes igualmente peligrosas en el aspecto higiénico. En dichas medidas deberá dar intervención a Jefatura Sanidad para evitar que los remitidos a lugares de su naturaliza puedan ser agentes transmisores de enfermedades...". Sabemos también que con fecha de 7 de abril de 1941 empezaron a prestar servicio en el Laboratorio Municipal, como topiqueros, para el Servicio de despiojamiento, José Sambruno Pérez y Emilia Ruiz Martín, con el sueldo de 8,50 pesetas diarias. Entre la documentación localizada se pueden comprobar partes de despiojamientos de personas en el Laboratorio Municipal de Higiene, correspondiente a los días 8, 9, 12, 14 y 15 (Protocolo Municipal 730, AMJF). De todas maneras, ya en enero de 1941 "fue despiojada" una mujer de domicilio desconocido, para tal fin se solicitó a la Superiora del Hospital Municipal el envío de una topiquera y un barbero, “desinfectándose la ropa por ebullición, y habiendo sido conducida en la Ambulancia al Hospital Municipal hasta el día de hoy en que se ha remitido la ropa ya desinfectada y seca".

Con fecha 9 de enero, el Jefe de la Sección de Epidemiología del Laboratorio Municipal, comunicó que la estufa de desinfección estaba 
Revista científica de la Asociación de Historia y Antropología de los Cuidados (Universidad de Alicante)

averiada, habiéndose avisado reiteradamente al mecánico para que diese presupuesto y remitirlo al Ayuntamiento para su aprobación (Protocolo Municipal 730, AMJF). En el mes de junio se avisa a través de una Circular, aparecida en el Boletín Oficial de la Provincia de Cádiz, que se procederá por la Alcaldía a la recogida de mendigos para su clasificación y envío a los pueblos de su naturaleza, así como que se proceda a organizar un Centro de desinsectación e higienización de mendigos, "donde serán pelados, despiojados y desinfectadas todas sus ropas, antes de ser enviados a su destino, y para su conducción a los puntos de residencia serán confiados a la Guardia Civil, a fin de que no puedan burlar las órdenes recibidas apeándose en estaciones de transito". Con fecha 4 de julio la Comandancia de la Guardia Municipal comunica al Alcalde que se han detenido e ingresado en el Destacamento del Balneario de San Telmo, indigentes procedentes de Ronda, Setenil, La Línea, El Bosque, Vigo, Sanlúcar de Barrameda, Arahal, Galera, Las Palmas, Sevilla, Palma del Río y Rota, con edades comprendidas entre los 17 y 66 años. Asimismo, existen documentos análogos, fechados el 6 de agosto, 7 de octubre y 7 de noviembre. A finales de diciembre de 1941, el Laboratorio Municipal solicita con carácter de urgencia formol, motivo por el que se hace necesario suspender el servicio de desinfección que diariamente se realiza por defunciones y pisos vacíos (Protocolo Municipal 730, AMJF).

El Jefe Provincial de Sanidad de Cádiz, Donato Fuejo, en el Boletín Oficial de la Provincia de Cádiz, dictó normas para las empresas (Fuejo, 1942). El propio Donato Fuejo envió al Inspector Secretario de la Junta Municipal de Sanidad de Jerez de la Frontera, una carta con fecha 11 de febrero de 1942, adjuntando carteles y circulares para su difusión y reparto con la finalidad de que sean conocidas por la población para defensa y limitación de la epidemia. Los carteles, indica Fuejo, deben ser expuestos en mercados, lavaderos, plazas, salas de espectáculos, casinos, bares, cafés, tabernas, etc. Y envía varias circulares, una destinada a los Maestros de Escuelas Nacionales y privadas, otra para las empresas privadas donde haya un contingente superior a 10 individuos, otra para las empresas de pompas fúnebres, otra para las salas de recreo y espectáculos diversos (bailes, cines, teatros, etc.), y otra para oficinas, juzgados y centros que no constituyan viviendas. Se hace mucho hincapié en la desinsectación, sirva como ejemplo la "Orden Circular comprendiendo prescripciones para la lucha contra el 
Cultura de los Cuidados

tifus exantemático en las grandes empresas privadas", de febrero de 1942. En la que se insiste en que la protección del personal se consigue por medio del despiojamiento, que debe afectar, por una parte, a las personas, y por otra, a las ropas de las mismas; la desparasitación de las primeras se logra mediante un baño jabonoso y las de las ropas por medio de cualquier sistema desinsectante, "entre los cuales hay que dar decidida preferencia a las cámaras de calor seco". Entre otras recomendaciones se apunta que es necesario que las empresas extiendan su radio de protección, "no sólo a todos sus empleados y obreros, sino también al círculo familiar de los mismos". En esta Circular se dan instrucciones para que todos los empleados y obreros, para poder trabajar, necesitan un certificado de limpieza familiar, expedido por el por el servicio médico de la empresa, con la inspección de esta Jefatura de Sanidad. En un plazo de 20 días las empresas quedan obligadas a montar y poner en funcionamiento las instalaciones sanitarias para asegurar el despiojamiento regular y periódico del personal y de las familias del mismo. Para la desinsectación de las personas se instalará el número necesario de duchas, con agua caliente y fría, y un pequeño servicio provisional de peluquería para pelar a aquellas que sean portadoras de parásitos de cabeza. Y para la desinsectación de las ropas se montará una o más estufas o cámaras de calor seco (veinte minutos a $80^{\circ}$ ), cuya capacidad asegure un rendimiento suficiente para los vestidos de todo el personal duchado.

Vista la Circular, algunas empresas se dirigieron al Ayuntamiento de Jerez indicándole el deseo “...de que puesto que la Corporación Municipal habrá también esa estación de desinsectación, fuera ampliado el proyecto para que resultase capaz a la utilización por todos, si bien como es lógico ello traería aparejado el que tales empresas contribuirian al gasto total". Visto lo cual el Ayuntamiento plantea lo siguiente:

"En su consecuencia y de conformidad con las conversaciones tenidas entre esta Alcaldía y vuestro Delegado Presidente, D. Enrique Fernández de Bobadilla, tengo el gusto de exponerle las condiciones de utilización por los afiliados de esa Sección Sindical de la Oficina de Desinsectación a construir por este Excmo. Ayuntamiento con la colaboración a donativos para ello, de otras entidades. Mediante la aportación por parte de esa Sección Sindical de 550.000 ptas. En tres plazos de 30,60 y 90 días respectivamente a ingresar por terceras partes a disposición de esta Alcaldía, en la Sucursal en esta plaza de Banco de España, c/c. abierta a nombre 
Revista científica de la Asociación de Historia y Antropología de los Cuidados (Universidad de Alicante)

'Estación Sanitaria' y quedando dicha

Oficina o Estación siempre de propiedad del Excmo. Ayuntamiento, tendrá derecho cada una de las afiliadas a esa repetida Sección Sindical, al despiojamiento gratuito de los obreros y empleados o dependientes...".

En agosto de 1942 el Jefe Provincial de Sanidad, Donato Fuejo, comunica al Alcalde de Jerez que se ha conseguido de la Dirección General de Sanidad una subvención de 81.373,15 pesetas. Sobre los pormenores de este convenio, entre las grandes empresas y el Ayuntamiento, para instalar el Centro de Desinsectación, se requiere que en el futuro se localice nueva documentación sobre el particular. Este es un aspecto en el que se entrecruza la salud pública y la economía empresarial sobre el que creemos se debe profundizar. Podemos apuntar sobre el tema que el Alcalde de Jerez, con fecha de 6 de julio de 1942, dirigió una carta a las Empresas de esta ciudad. Dice así:

"Que los patronos que pertenezcan al Sindicato de Exportadores, no tienen que hacer declaración para sus obreros $y$ empleados de bodegas ya que el Sindicato concierta con el Ayuntamiento este servicio y el pago será diferente para los que no entren este concierto. Los demás productores presentarán la relación nominal de los obreros y dependencias en el
Negociado de Beneficencia y Sanidad" (Legajo 1.169, Expediente 24769, AMJF).

Durante el año 1942 se recibieron 461.680,52 pesetas para la lucha contra el tifus exantemático en la provincia de Cádiz, que fueron distribuidas en jornales, remuneraciones, estancias hospitalarias, diversos materiales e instalaciones. De esta cantidad, se invirtió un total de $190.676,52$ pesetas en Cádiz capital y 111.809,95 en Jerez de la Frontera, el resto de la inversión se hizo en las localidades de San Fernando, Puerto Real, El Puerto de Santa María y Chiclana (Fuejo, [1943]).

En 1942 la prensa jerezana siguió dando noticias sobre el aseo y la higiene, por ejemplo, incluso demandando medidas punitivas para las persona sucias (“Ayer", 17-1-1942). Leamos:

"El agua no cuesta dinero. El sucio que la rechaza, debe también por sus conciudadanos ser repudiado, debiendo ser denunciado a la autoridad, para que lo detenga y le imponga el castigo. No debemos consentir de ningún modo ese espectáculo (...), de chiquillos y mayores, que, con costras en manos y pies $y$, a veces, en la cara, van por donde van, paseando un constante foco de infección...". 
Cultura de los Cuidados

También se hacen anuncios en la prensa de que la mendicidad callejera va a desaparecer radicalmente, "ha sido afrontado el problema y los niños que pululan por la vía pública serán recogidos y atendidos", para lo cual el alcalde convoca una reunión para organizar la "Junta Local Benéfica", abriendo suscripciones voluntarias y anunciando que inmediatamente se recogerán a los niños vagabundos para que ingresen en instituciones para ser educados, vestidos y alimentados (“Ayer”, 20-I-1942). Entre las medidas se aprobó un dictamen de la Comisión de Beneficencia, sobre la construcción de tres barracones en las proximidades del Balneario de San Telmo, para acoger a los mendigos que se retiren de la población. Se aprobó el proyecto del Arquitecto Municipal y se acuerda solicitar subvención al Ministerio de la Gobernación (“Ayer”, 22-I-1942). Ya hemos comentado anteriormente, al exponer los centros que se organizaron para plantear la lucha contra el tifus exantemático en Jerez, que finalmente no se construyeron tres barracones, consiguiéndose presupuesto para construir uno.

El Jefe Provincial de Sanidad, en febrero de 1942, publica en la prensa jerezana órdenes y circulares, en lo referido a las empresas privadas, concretamente sobre los certificados de limpieza de los empleados y sus familias, y la inspección y comprobación de los servicios, aspectos sobre los que ya hemos insistido ("Ayer", 6-III-1942). Igualmente en lo que se refiere a instrucciones a los empleados de pompas fúnebres $\mathrm{y}$ empresas que se ocupen en el manejo y transporte de cadáveres, también en lo referido a la desinfección de teatros y salas de espectáculos, de oficinas, juzgados y comisarías ("Ayer", 7,8 y 11-III-1942).

El 12 de marzo se publica una Orden Circular, dirigida a los médicos, para la lucha contra el tifus exantemático, entre las que destacan que los enfermos y familiares se hallen libres de piojos, extender cuando lo crean conveniente un vale para jabón que los interesados presentarán en la Oficina de Sanidad para su refrendo, proporcionándoselo previo su pago o gratuitamente, según la posición económica de la familia. Se recomienda que el servicio de enfermeras se encargue de comprobar si el producto se emplea en las prácticas de la limpieza de la familia. Se insiste en que los casos "sospechosos" o confirmados de tifus exantemático, deben ser notificados a la Oficina de Sanidad, por teléfono o en forma de parte. En cuanto al aislamiento se recomienda en enfermos o familias parasitadas, enfermos en extrema miseria total, enfermos que voluntariamente lo piden y enfermos 
Revista científica de la Asociación de Historia y Antropología de los Cuidados (Universidad de Alicante)

mal asistidos. Asimismo se ofrecen instrucciones sobre las fichas epidemiológicas, en las que debe constar el aspecto del paciente, el contacto intrafamiliar, y en cuanto a la pediculosis, si está limpio, si tiene liendres $\mathrm{o}$ pocos piojos adultos (“Ayer", 12-III-1942).

El 18 de marzo, el alcalde de Jerez, Eduardo Delage, publica en la prensa instrucciones sanitarias sobre la vigilancia de todos los viajeros procedentes de Madrid, Málaga, San Fernando y Puerto Real. Este servicio de vigilancia se establece en la Oficina Municipal de Sanidad, en la planta baja de las Casas Consistoriales, en horario de 10 a 13 y de 16 a 17,30 . Por este motivo los dueños o gerentes de hoteles, pensiones, fondas, casas de huéspedes, posadas, paraderos y casas de dormir tienen la obligación inexcusable de comunicar a los viajeros que lleguen de esas poblaciones, $u$ otras en la que exista dicha enfermedad, la obligación de presentarse en la Oficina Municipal de Sanidad ("Ayer", 18-III1942).

Una de las preocupaciones del Jefe Provincial de Sanidad, Donato Fuejo, expuesta en su Informe sobre la epidemia de tifus exantemático en la provincia de Cádiz fue, como hemos indicado, el despiojamiento en el foco y en la vecindad, por eso insistió mucho en las visitas domiciliarias sistemáticas, para la desparasitación de personas y ropas de las familias "recalcitrantemente sucias". Por este motivo se procuró "el funcionamiento de equipos de muchachas que se dedican a realizar este trabajo sistemático de visita a las viviendas". Según Fuejo estas visitas a las viviendas fueron ampliadas, incluyéndolo entre los trabajos rutinarios de las "visitadoras" (Fuejo [1943]):

“...todo lo que se denomina campaña contra la mortalidad infantil y contra la tuberculosis, y asi hemos realizado durante el verano, una formidable labor de vacunación antivariólica, antidiftérica y antitífica; hemos acercado al Dispensario a muchísimas madres y niños necesitados de conocer los servicios de higiene infantil $y$ tuberculosis, hemos estimulado también el tratamiento de la sarna y otras enfermedades parasitarias del pelo y cuero cabelludo. Esta campaña de las visitadoras es la indicada para descubrir la existencia de Escuelas clandestinas llamadas "Migas", que son peligrosísimas, sanitariamente consideradas, ya que a ellas acuden en gran proporción todos aquellos niños excluidos de las escuelas oficiales por padecer enfermedades que motivan estas exclusiones, todas ellas en general contagiosas, $y$ en estos locales se hacinan numerosísimos 
niños en aulas pequeñisimas, unos

afectos de conjuntivitis, otros de

parasitismo, otros de sarna, otros de eczemas, impétigos...".

En la campaña contra el tifus exantemático del año 1942, Donato Fuejo ofrece datos de diferentes localidades de la provincia como Barbate, Chiclana, San Fernando, El Puerto de Santa María, Cádiz y Jerez de la Frontera. Por ejemplo se hicieron visitas domiciliares a "focos" y otras "sistemáticas". En total, en lo que se refiere a Jerez de la Frontera se visitaron 7.571 familias, de las cuales estaban limpias 7.219 y 352 estaban parasitadas y se realizaron despiojamientos, en cuanto a duchas y desinsectaciones se apunta la cifra de 15.992. En lo referido a Cádiz capital fueron 6.158 familias visitadas, de las cuales 4.812 estaban limpias y 1.346 estaban parasitadas y fueron despiojadas, en cuanto a duchas $\mathrm{y}$ desinsectaciones se apuntan 29.164. En todas las localidades citadas se visitaron a 35.567 familias, de las cuales estaban parasitadas y fueron despiojadas 9.854, con un total de 88.697 duchas y desinsectaciones. Se debe apuntar que en estas 6 localidades citadas trabajaron en la lucha contra el tifus exantemático:

Enfermeras: 54; Mozos: 10; Facultativos-Médicos: 7; Administrativos: 3; Practicantes: 2; Sacerdote: 1 (Fuejo [1943]).

\section{5.- Epílogo}

En este apartado vamos a realizar varias recapitulaciones y reflexiones sobre las cifras de morbilidad $y$ mortalidad de la epidemia, así como sobre la situación social en la ciudad de Jerez de la Frontera. Lo primero que queremos subrayar es que cuando se consultan diferentes fuentes documentales pueden aparecer diferentes cifras o bien de morbilidad o de mortalidad, con mayor o menor diferencia, esto puede suceder cuando consultamos los datos que ofrecen los libros del movimiento natural de la población de esos años, los libros de registro de defunciones del Cementerio, que se encuentran en el Archivo Municipal de Jerez, o las memorias de sanitarios como Donato Fuejo, José Estrade Camúñez o Salvador Dastis.

Algunos ejemplos prácticos de lo que decimos; en lo referido a la morbilidad de 1942 encontramos que Palanca anota, en lo que se refiere a la provincia de Cádiz, en el año 1942, la cifra de 1.252 enfermos de tifus exantemático, mientras que Donato Fuejo apunta 1.319. En lo referido a la mortalidad llama la atención que los libros del Movimiento Natural de la Población señalan 61 defunciones por tifus exantemático en la provincia de Cádiz en 1941 y en lo que respecta al 
año 1942 se apunta 176 (Herrera

Rodríguez, 1997). Esto contrasta con las cifras que apunta Donato Fuejo: 86 defunciones, en el año 1941, para un cómputo de 16 localidades de la provincia de Cádiz; y 152 defunciones, en el año 1942, cómputo de 15 localidades de la provincia de Cádiz. Cifras cuyas diferencias llaman la atención y nos hacen pensar que en algún caso no se computaran defunciones de otras localidades de la provincia de Cádiz, o bien en algún tipo de error de transcripción o de imprenta, o en alguna otra circunstancia que habría que descubrir.

Sucede algo parecido, aunque son menores las diferencias, en lo referido al tifus exantemático en la ciudad de Jerez de la Frontera. Por ejemplo, Donato Fuejo señala 24 defunciones en 1941 y 2 defunciones en 1942, como ya hemos indicado; José Estrade apunta 26 y 1 defunciones, respectivamente, para los años señalados; y Salvador Dastis, en su Memoria correspondiente al año 1942 apunta 2 defunciones (Cf. Apéndices documentales 1, 2 y 3). Sobre este particular, en este artículo, hemos comentado ya nuestra indagación en los libros de Registro de Defunciones del Cementerio que se encuentran en el Archivo Municipal de Jerez de la Frontera, apuntando cifras aproximadas.
A la hora de hallar las tasas, hemos tenido en cuenta que Estrade apunta un total de 2.303 defunciones en Jerez en $1941 \mathrm{y}$ en 1942 un total de 1.486. Considerando la población existente en los respectivos años en la ciudad de Jerez en los referidos años (tabla 1), encontramos que la tasa de mortalidad general en el año 1941 es de 25,65 (por mil) y en 1942 es de 16,39 (por mil). Salvador Dastis en su Memoria correspondiente al año 1942, señala en cambio 1548 defunciones en Jerez y apunta 89.525 habitantes, siendo la tasa de mortalidad general en ese año, según estos datos, de 17,29 (por mil).

En lo referido a la tasa de mortalidad específica del tifus exantemático, en 1941, teniendo en cuenta las 26 defunciones que señala Estrade Camúñez, encontramos que es de 28,95 (por cien mil). $\mathrm{Y}$ esta misma tasa, considerando las 24 defunciones señaladas por Fuejo, es de 26,73 (por cien mil). En lo que se refiere al año 1942, Estrade señala 1 defunción, siendo la tasa de mortalidad específica de 1,1 (por cien mil). Mientras que en los casos de Fuejo y Dastis, que señalan 2 defunciones, la tasa resultante es de 2,2 (por cien mil).

Según apunta Estrade Camúñez, en su Memoria del Laboratorio del año 1959, quedó resuelta la epidemia en 
1942, "sin que se hayan dado casos hasta el día de hoy". Para concluir con este punto, debemos añadir que la "Reseña Estadística de la provincia de Cádiz", publicada en 1957, ofrece la información de que en la provincia gaditana, entre 1941-1945, fallecieron 159 hombres por el tifus exantemático y 104 mujeres, sumando 263 defunciones por esta enfermedad. En el período de 1946 a 1950 este documento señala que sólo hubo una defunción en la provincia gaditana. La cuestión es la siguiente: Sabiendo los problemas existentes en la época para confeccionar las fichas epidemiológicas, y por tanto para computar los casos que realmente se produjeron, y los problemas existentes, por diversos motivos, para reflejar en los partes de defunción las causas que la motivaron, nos preguntamos, ¿no serían realmente algunos casos más y algunas defunciones más las provocadas por esta enfermedad en Jerez de la Frontera y en la provincia de Cádiz? De hecho, recientemente, en lo referido al tifus exantemático en la ciudad de Valencia, se ha apuntado la sospecha de una infradeclaración, tanto de enfermos como defunciones por esta enfermedad (García Ferrandis y Martínez Vidal, 2017). De hecho hemos comentado anteriormente la posibilidad de casos leves "indiagnosticados", según terminología de la época. No cabe duda, que todos estos problemas están abierto a futuras investigaciones.

$\mathrm{Si}$ el tifus exantemático fue un problema en España y en Jerez de la Frontera, en 1941 y 1942, no lo fueron menos otras enfermedades, en cuanto a casos y a defunciones. Por ejemplo, Salvador Dastis señala que en Jerez nada menos que enfermaron 3.943 personas por paludismo y que por tuberculosis murieron 190 persona, por meningitis 51, por cáncer y otros tumores malignos 145, por fiebre tifoidea 23, por accidentes, suicidios y muertes violentas 46, etc. No agotamos el catálogo de casos y defunciones, sólo queremos señalar que otras enfermedades físicas, psíquicas y sociales estaban dañando sobremanera a la población jerezana (Cf. Apéndices documentales). Véanse los datos que sobre las defunciones por enfermedades infecciosas y por tuberculosis, entre los años 1937 y 1959, aportados por Estrade Camúñez (tabla 7). Sobre el problema de la tuberculosis en Jerez de la Frontera véanse también los comentarios de Mariscal Trujillo (2001). Sobre todas estas cuestiones insistiremos en futuros trabajos, teniendo en cuenta las Memorias del Laboratorio Municipal de Higiene de Jerez de la Frontera, redactadas por José Estrade Camúñez, que ofrecen información de morbilidad y mortalidad, un esfuerzo notable del médico gaditano, afincado en Jerez, que merece que abordemos de forma monográfica. 
En este artículo a través de algunas tablas ofrecemos datos que creemos de interés para enmarcar la problemática socio-sanitaria de la ciudad.

Igualmente Estrade Camúñez ofrece datos de morbilidad sobre el paludismo entre 1943 y 1953 (tabla 8).

Y todo esto sin olvidarnos de enfermedades como la fiebre tifoidea, la meningitis, la difteria, etc. Por ejemplo, Estrade Camúñez, sobre la fiebre tifoidea apunta que se produjeron en 1941 y 1942, respectivamente, 240 y 132 casos. Y, evidentemente, no podemos olvidarnos de la mortalidad infantil (Bernabeu-Mestre et al, 2006); por ejemplo, Estrade Camúñez apunta para 1941 sobre los fallecidos menores de 1 año, por cada mil nacidos vivos, una media en el año de 211,76 y para 1942 de 123,23 (Cf. Apéndices documentales 1 y 2).

La prensa jerezana, en agosto de 1942, resaltó la labor de la Sección Femenina en la lucha contra la mortalidad infantil, señalando que por cada mil niños nacidos vivos en España, fallecen anualmente 120 menores de un año. Señala también que pocos países europeos lo rebasan, apunta como la cifra más baja la de Islandia con 28 por mil, siguiéndole los Países Bajos con 37, mientras que Suecia, Noruega y Suiza, oscilan entre 41 y 43; otros países como Dinamarca, Inglaterra, Francia, Irlanda, Bélgica y Australia, de 59 a 83 por mil. En este artículo llama la atención como se da la noticia de que la Sección Femenina y de Falange, realizan campañas de divulgación veraniega para combatir "por medio de la propaganda y de las lecciones prácticas de las enfermeras divulgadoras la ignorancia de tantas madres españolas en cuanto a se refiere a la crianza y cuidado de los niños" ("Ayer", 25VIII-1942).

Como se puede apreciar estos párrafos reflejan lo que hace unos años expuso Bernabeu-Mestre (2002):

“...dos eran las causas que se consideraban como fundamentales para explicar las cifras que mostraba la mortalidad infantil española: la ignorancia y la miseria (...). La mortalidad infantil se consideraba, en gran medida, evitable $y$ se culpabilizaba a las madres llegando, incluso, a responsabilizarlas de alcanzar el objetivo. Se planteaba la necesidad de llevar a cabo una extensa, intensa y bien dirigida campaña de 'propaganda y divulgación sanitaria' cumpliendo, así, los deseos del 'Generalísimo' de dar preferencia a los asuntos de maternología ypuericultura”.

Bernabeu señala que en la línea del discurso culpabilizador de las madres, se destacaba fundamentalmente el abandono de la lactancia materna, la alimentación inadecuada, la presencia de vómitos $\mathrm{y}$ diarreas durante el período de lactancias debido a las prácticas antihigénicas y al desconocimiento de las normas de la puericultura. En esta línea se pueden ver, entre otros, publicaciones de Juan Bosch Marín como "La asistencia sanitaria a la madre y al niño" (1942) y "Trabajo, maternidad y lactancia” (1943) (Bernabeu-Mestre, 2002).

El 1 de enero de 1942, la prensa jerezana, publicó un resumen del año anterior, señalando algunos problemas fundamentales en la vida 
de los jerezanos, por ejemplo: el problema de abastecimiento (cartillas de racionamiento), sobre el que ya hemos hecho algunos comentarios; el problema de la vivienda; y la lucha contra "una epidemia terrible" y contra la mortandad ("Ayer", 1-I-1942).

Sobre la epidemia hemos dedicado algunas páginas en este artículo, pero observamos que el tema de la vivienda en Jerez en los años 40 requiere de investigaciones específicas, como por ejemplo el seguimiento de la construcción de 881 viviendas protegidas en el Barrio de la Plata y en San José del Valle, en este sentido en el mes de mayo de 1942 la prensa jerezana apunta lo siguiente ("Ayer", 17V-1942):

"En Jerez, desde el primer Ayuntamiento que rigió los destinos de la ciudad en el Movimiento, todos han sentido la preocupación agobiante en este problema que en nuestra ciudad adquiere caracteres trágicos por la verdadera escasez de viviendas después del aumento notable de la población".

Sobre el racionamiento hemos hecho algunos comentarios en los capítulos introductorios de este trabajo, pero en Jerez se observa que el hambre apretó a la población y que los mecanismos de la caridad se activaron a través de la "Junta Benéfica local". Una Junta Benéfica creada por el alcalde con la "cooperación de relevantes personalidades". Se alega que las limosnas que se entregan en la calle a los "pedigüeños profesionales", fomentan la vagancia y prostituye las costumbres y destruyen el hábito del trabajo. Se alienta a que se invierta en el "sello benéfico" para mantener los ocho comedores públicos que sostiene la citada Junta ("Ayer", 14-VIII-1942).
Después de estos últimos apuntes queremos recordar que Jiménez Lucena (1990), en su trabajo sobre el tifus en la Málaga de la posguerra, subrayó el hacinamiento y la infranutrición endémica en los medios populares como factores que deben tenerse en cuenta para entender el desarrollo del tifus exantemático. Si observamos la tabla 1 no se observa un incremento notable de la población en Jerez entre los años 1940 y 1942, pero esto no descarta el hacinamiento de personas en situaciones que podríamos calificar de infravivienda y como hemos podido ver los problemas de alimentación eran muy importantes. Tanto que, además de todo lo apuntado sobre la Junta Benéfica Local, se empiezan los trámites para establecer la "Cartilla Nacional-Sindicalista", a partir del 16 de mayo de 1942, para los "productores en paro forzoso". El Bando del Alcalde, Eduardo Delage, está firmado el día 6 de mayo, impresiona sobremanera este texto. Leamos ("Ayer", 7-V-1942):

"A partir del 16 del actual será implantada en esta Ciudad la Cartilla Nacional Sindicalista, mediante la cual el productor que se encuentre en paro forzoso e igualmente todos sus familiares, tendrán derecho a que se les facilite gratuitamente de momento-, el pan correspondiente a él y sus familiares, beneficio que podrá ampliarse a los demás artículos de racionamiento, tan pronto sea posible. Para poder utilizar la indicada cartilla, será necesario que el productor en paro y cada uno de sus familiares comparezcan diariamente en la oficina que a tal fin ha de establecerse en la Delegación Local de Auxilio Social, debiendo exhibir el productor el carnet de la Oficina Local de Colocación Obrera que la acredite como parado, asi como las cartillas de racionamiento suya y de sus familiares, con el fin de cortar a cada una el cupón de pan del dia siguiente al de que se trate, y 
Revista científica de la Asociación de Historia y Antropología de los Cuidados (Universidad de Alicante)

entregarles a su vez un vale que presentarán en el Establecimiento donde se surtan de pan, sirviéndole su entrega de abono del expresado artículo. Si algún productor en paro llegara a trabajar en ocasiones algunos días en la semana, dichos días no recogerá el pan ni el de sus familiares, pero tan pronto como quede nuevamente parado, le será facilitado (...). Para allegar fondos con tal fin, todos los poseedores de cartillas de racionamiento habrán de abonar mensualmente cinco pesetas por cada una de primera; dos pesetas por cada una de segunda, y una peseta por las de tercera (...). Aquellas personas que por su situación financiera y escasez de familia se encuentre en posición desahogada serán invitadas a efectuar ingresos supletorios".

Impresiona, como hemos indicado, esta información de prensa sobre el pan de los "productores" en paro y sus familias, así como los de la Junta Benéfica o el planteamiento del plan de viviendas. Abren en canal los problemas que tenían las personas pobres en Jerez; a algunos, en relación con el tifus exantemático, se les llamaba "piojosos" o incluso también se incluyó en esta problemática a los gitanos. En este sentido ya se ha señalado que el tifus fue considerado un rasgo característico de "razas inferiores", como por ejemplo los gitanos (Rodríguez-Ocaña, 2017).

Pero también cabe recordar que Donato Fuejo García, Jefe Provincial de Sanidad de Cádiz, reclamaba respeto, exponiendo en su Informe, ayudaran los Alcaldes de la provincia o no, que:

"desde el primer día también quisimos convencer a las autoridades y al público de que la lucha contra el tifus exantemático no la podíamos realizar los sanitarios exclusivamente, ya que las causas que motivan la extensión del mal no eran típicamente sanitarias, sino económico-sociales, como la miseria de las gentes, carencia de ropa, escasez de alimentación y sobre todo malas viviendas que, en la mayor parte de los casos, eran chozas, cuya cubicación la mayor parte de ellas no pasaba de 30 o 40 metros cúbicos, se realizaban todos los actos de la vida familiar: cocinar, estar, dormir, etc., todo ello, como es natural, en la mayor promiscuidad, sin separación ni de sexos ni de edades, por lo cual publicamos una serie de instrucciones divulgadoras de las causas del tifus exantemático y su agente propagador y de las medidas que eran dable realizar tanto a los individuos como a las distintas organizaciones: Ayuntamientos, escuelas, industriales y, dentro de éstas, aquellas más importantes y las dedicadas al tráfico de pasajeros" (Fuejo, [1943]).

No quedaron aquí las matizaciones de Donato Fuejo sobre esta Campaña contra el tifus exantemático, que requería de sutilezas que invadían la intimidad de las personas. Dice así (Fuejo, [1943]):

"La organización de una Lucha sanitaria contra el tifus exantemático, es, a nuestro juicio, una de las actuaciones sanitarias más difíciles y complejas; nace esta dificultad fundamental de que con nuestras medidas tenemos que intervenir $y$ muchas veces molestar la intimidad de las personas y de sus hogares, la cual rechazamos todos violentamente, necesitándose una comprensión de la utilidad de estas medidas para tolerarlas y aceptarlas, cuya comprensión únicamente cierta parte de la población con un nivel cultural grande y un sentido de responsabilidad ciudadana siente en grado adecuado".

Donato Fuejo García, en el referido Informe, sostiene que en una lucha contra una epidemia como ésta, se requiere de: 
"...una energía ejercida

sostenidamente; mucha prudencia; mucho tacto; mucha cortesía y afecto hacia las gentes, demostrando por sus problemas interés real y hacerles ver que se si sitúa uno en su posición y lamenta profundamente las molestias que necesariamente tenemos que causarles en aras del bien colectivo, del de sus familiares y del suyo propio; o sea, que necesitamos conquistarnos la adhesión de todo el público, haciéndonos perdonar nuestra intervención”.

Este discurso humanista de Donato Fuejo, florecido de empatía, no lo mantuvieron otros en la prensa jerezana, como hemos podido comprobar, señalando y culpando a madres, a los pobres y a los gitanos, incluso utilizando el término "piojosos".

El tifus exantemático, pues, fue un problema grave añadido a la sociedad jerezana; pero en estos años tan duros otras enfermedades se estaban llevando por delante a las personas, hemos intentado dejar constancia de ello también. No creo que muchas de estas personas pudieran leer en la prensa de Jerez una noticia emitida desde Milán, que si lo pensamos bien lleva un título casi de un cuento de Gabriel García Márquez: "Un pez de peso se había tragado un brillante" ( "Ayer", 14-VI1942). Dice así la breve crónica: “Un pescador de Nogares encontró en su red a un pez que pesaba dos kilos. Abierto el pez se le halló dentro un brillante que vale más de 200.0000 francos.-Efe".

¿Cuántos jerezanos pobres soñarían con ese brillante o tan solo con un trozo de pan? Sobre todo cuando encontramos en el Archivo Municipal de Jerez de la Frontera, documentos en los que se relacionan centenares de indigentes, en los años 40, que estudiaremos en otro trabajo. Lo intentaremos, porque las tasas $\mathrm{o}$ coeficientes de morbilidad y mortalidad son importantes, pero también los documentos que abren en canal la vida cotidiana de las personas que más sufren en una sociedad, en este caso de los que más sufrieron en Jerez de la Frontera, en esos tiempos de hambre, miseria, endemias y epidemias.

\section{Apéndices documentales}

En este apartado presentamos tres apéndices documentales: Primero, resumen de la Memoria del Laboratorio Municipal de Higiene en 1941, redactada por José Estrade Camúñez; Segundo, resumen de la Memoria del Laboratorio Municipal de Higiene en 1942, redactada por el mismo autor; y, tercero, Informe de Salvador Dastis sobre los datos estadísticos recopilados durante el año de 1942 en la Oficina Municipal de Sanidad.

Agradecimientos: A don Manuel S. Estrade Pando, por la donación de la documentación de su padre, don José Estrade Camúñez, al Archivo Municipal de Jerez y por toda la información que me ha proporcionado en las entrevistas personales que hemos tenido. A Cristóbal Orellana González, Responsable Técnico del AMJF, que me avisó de la existencia de esta documentación $\mathrm{y}$ ha resuelto con la paciencia de siempre todas las dudas que le he planteado. $\mathrm{Y}$ a todo el personal del AMJF. También al personal de la Biblioteca Pública Provincial de Cádiz, donde he consultado el periódico jerezano "Ayer", y que pusieron a mi disposición el Informe de Donato Fuejo sobre el tifus exantemático en la provincia de Cádiz, tras las gestiones pertinentes con la Biblioteca de Andalucía (Granada). Y a todo el personal del Archivo Municipal de Cádiz que durante los 
Revista científica de la Asociación de Historia y Antropología de los Cuidados (Universidad de Alicante)

años 90 me ayudaron siempre en las investigaciones realizadas sobre el tifus exantemático en Cádiz.

\section{FUENTES DOCUMENTALES}

-“Ayer", periódico de Jerez de la Frontera, 1 de abril de 1941 (Biblioteca Pública del Estado-Biblioteca Provincial de Cádiz). Abreviatura para la cita interna: "Ayer", 1-IV-1941).

-“Ayer”, periódico de Jerez de la Frontera, 6 de abril de 1941 (Biblioteca Pública del Estado-Biblioteca Provincial de Cádiz). Abreviatura para la cita interna: "Ayer", 6-IV-1941).

-“Ayer”, periódico de Jerez de la Frontera, 8 de abril de 1941 (Biblioteca Pública del Estado-Biblioteca Provincial de Cádiz). Abreviatura para la cita interna: "Ayer", 8-IV-1941).

-“Ayer”, periódico de Jerez de la Frontera, 3 de mayo de 1941 (Biblioteca Pública del EstadoBiblioteca Provincial de Cádiz). Abreviatura para la cita interna: “Ayer", 3-V-1941).

-“Ayer", periódico de Jerez de la Frontera, 9 de mayo de 1941 (Biblioteca Pública del EstadoBiblioteca Provincial de Cádiz). Abreviatura para la cita interna: “Ayer”, 9-V-1941).

-"Ayer", periódico de Jerez de la Frontera, 16 de mayo de 1941 (Biblioteca Pública del EstadoBiblioteca Provincial de Cádiz). Abreviatura para la cita interna: “Ayer”, 16-V-1941).

-“Ayer", periódico de Jerez de la Frontera, 18 de mayo de 1941 (Biblioteca Pública del EstadoBiblioteca Provincial de Cádiz). Abreviatura para la cita interna: “Ayer”, 18-V-1941).
-"Ayer", periódico de Jerez de la Frontera, 20 de mayo de 1941 (Biblioteca Pública del EstadoBiblioteca Provincial de Cádiz). Abreviatura para la cita interna: “Ayer", 20-V-1941).

-“Ayer", periódico de Jerez de la Frontera, 21 de mayo de 1941 (Biblioteca Pública del EstadoBiblioteca Provincial de Cádiz). Abreviatura para la cita interna: “Ayer", 21-V-1941).

-“Ayer”, periódico de Jerez de la Frontera, 6 de junio de 1941 (Biblioteca Pública del Estado-Biblioteca Provincial de Cádiz). Abreviatura para la cita interna: "Ayer", 6-VI-1941).

-“Ayer", periódico de Jerez de la Frontera, 15 de junio de 1941 (Biblioteca Pública del EstadoBiblioteca Provincial de Cádiz). Abreviatura para la cita interna: “Ayer”, 15-VI-1941).

-“Ayer", periódico de Jerez de la Frontera, 1 de enero de 1942 (Biblioteca Pública del EstadoBiblioteca Provincial de Cádiz). Abreviatura para la cita interna: “Ayer", 1-I-1942).

-“Ayer", periódico de Jerez de la Frontera, 17 enero de 1942 (Biblioteca Pública del Estado-Biblioteca Provincial de Cádiz). Abreviatura para la cita interna: “Ayer”, 17-I-1942).

-"Ayer", periódico de Jerez de la Frontera, 20 enero de 1942 (Biblioteca Pública del Estado-Biblioteca Provincial de Cádiz). Abreviatura para la cita interna: “Ayer”, 20-I-1942).

-“Ayer", periódico de Jerez de la Frontera, 22 enero de 1942 (Biblioteca Pública del Estado-Biblioteca Provincial de Cádiz). Abreviatura para la cita interna: "Ayer”, 22-I-1942).

-“Ayer", periódico de Jerez de la Frontera, 6 de marzo de 1942 
(Biblioteca Pública del Estado-

Biblioteca Provincial de Cádiz). Abreviatura para la cita interna: “Ayer", 6-III-1942).

-“Ayer", periódico de Jerez de la Frontera, 7, 8 y 11 de marzo de 1942 (Biblioteca Pública del EstadoBiblioteca Provincial de Cádiz). Abreviatura para la cita interna: “Ayer", 7, 8 y 11-III-1942).

-“Ayer", periódico de Jerez de la Frontera, 12 de marzo de 1942 (Biblioteca Pública del EstadoBiblioteca Provincial de Cádiz). Abreviatura para la cita interna: “Ayer”, 12-III-1942).

-"Ayer", periódico de Jerez de la Frontera, 18 de marzo de 1942 (Biblioteca Pública del EstadoBiblioteca Provincial de Cádiz). Abreviatura para la cita interna: “Ayer”, 18-III-1942).

-“Ayer", periódico de Jerez de la Frontera, 7 de mayo de 1942 (Biblioteca Pública del EstadoBiblioteca Provincial de Cádiz). Abreviatura para la cita interna: “Ayer", 7-V-1942).

-“Ayer", periódico de Jerez de la Frontera, 17 de mayo de 1942 (Biblioteca Pública del EstadoBiblioteca Provincial de Cádiz). Abreviatura para la cita interna: “Ayer”, 17-V-1942).

-“Ayer", periódico de Jerez de la Frontera, 14 de junio 1942 (Biblioteca Pública del Estado-Biblioteca Provincial de Cádiz). Abreviatura para la cita interna: “Ayer”, 14-VI-1942).

-“Ayer", periódico de Jerez de la Frontera, 14 de agosto 1942 (Biblioteca Pública del Estado-Biblioteca Provincial de Cádiz). Abreviatura para la cita interna: "Ayer", 14-VIII-1942).

-"Ayer", periódico de Jerez de la Frontera, 25 de agosto 1942 (Biblioteca
Pública del Estado-Biblioteca Provincial de Cádiz). Abreviatura para la cita interna: "Ayer”, 25-VIII-1942).

-Carta del Presbítero Rafael Serrano (1941). En: Protocolo Municipal 730 (antiguo 676). Documentos de Alcaldía (Año 1941) (Archivo Municipal de Jerez de la Frontera, AMJF).

-Cellier Ortega, J.I. (1909a): “Tifus exantemático. Su historia, etiología y profilaxis". La Medicina Práctica, VIII, 88, 271-276.

-Cellier Ortega, J.I. (1909b): “Concepto clínico del tifus exantemático". La Medicina Práctica, VIII, 89, 287-293.

-Cellier Ortega, J.I. (1909c): "Tratamiento del tifus exantemático". La Medicina Práctica, VIII, 90, 307308.

-Cementerio 448 (Justificantes de enterramientos. Enero y febrero de 1941). Archivo Municipal de Jerez de la Frontera, AMJF.

-Cementerio 449 (Justificantes de enterramientos. Febrero y marzo de 1941). Archivo Municipal de Jerez de la Frontera, AMJF.

-Cementerio 450 (Justificantes de enterramientos. Abril y mayo de 1941). Archivo Municipal de Jerez de la Frontera, AMJF.

-Cementerio 451 (Justificantes de enterramientos. Junio 1941). Archivo Municipal de Jerez de la Frontera, AMJF.

-Cementerio 452 (Justificantes de enterramientos. Julio 1941). Archivo Municipal de Jerez de la Frontera, AMJF.

-Cementerio 453 (Justificantes de enterramientos. Agosto 1941). Archivo Municipal de Jerez de la Frontera, AMJF. 
-Cementerio 454 (Justificantes de enterramientos. Septiembre-Octubre, 1941). Archivo Municipal de Jerez de la Frontera, AMJF.

-Cementerio 455 (Justificantes de enterramientos. Noviembre-Diciembre, 1941). Archivo Municipal de Jerez de la Frontera, AMJF.

-Cementerio 458 (Justificantes de enterramientos. Mayo y Junio, 1942). Archivo Municipal de Jerez de la Frontera, AMJF.

-Cementerio 459 (Justificantes de enterramientos. Julio y Agosto, 1942). Archivo Municipal de Jerez de la Frontera, AMJF.

-Cementerio 467 (Justificantes de enterramientos. Noviembre y diciembre de 1943). Archivo Municipal de Jerez de la Frontera, AMJF.

-Comunicado al Alcalde de Jerez sobre tifus exantemático en la cárcel (1941). En: Protocolo Municipal 730 (antiguo 676). Documentos de Alcaldía (Año 1941) (Archivo Municipal de Jerez de la Frontera, AMJF).

-Estadística. Sección N. General. Relación detallada de los habitantes de esta población del 1859-1960. Legajo 3877, expediente 33949 (Archivo Municipal de Jerez de la Frontera). Abreviatura para la cita interna del artículo: Población 1859-1960 (Legajo 3877, expediente 33949, AMJF).

-Estrade Camúñez, J. (1941). Bando. Laboratorio Municipal de Higiene de Jerez de la Frontera. Divulgación de conocimientos sanitarios y de Higiene. Este documento se puede consultar en el AMJF, en la documentación cedida por don Manuel S. Estrade Pando).

-Estrade Camúñez, J. (1938): Memoria del Laboratorio Municipal de Higiene en 1937. Ayuntamiento de Jerez de la Frontera. Imprenta Municipal: Jerez. (Documento cedido por Manuel S.
Estrade Pando al Archivo Municipal de Jerez de la Frontera, AMJF., donde se puede consultar).

-Estrade Camúñez, J. (1939): Memoria del Laboratorio Municipal de Higiene en 1938. Ayuntamiento de Jerez de la Frontera. Imprenta Municipal: Jerez. (Documento cedido por Manuel S. Estrade Pando al Archivo Municipal de Jerez de la Frontera, AMJF, donde se puede consultar).

-Estrade Camúñez, J. (s.f.e.): Memoria del Laboratorio Municipal de Higiene en 1939. Ayuntamiento de Jerez de la Frontera. Imprenta Municipal: Jerez. (Documento cedido por Manuel S. Estrade Pando al Archivo Municipal de Jerez de la Frontera, AMJF, donde se puede consultar).

-Estrade Camúñez, J. (s.f.e.): Memoria del Laboratorio Municipal de Higiene en 1940. Ayuntamiento de Jerez de la Frontera. Imprenta Municipal: Jerez. (Documento cedido por Manuel S. Estrade Pando al Archivo Municipal de Jerez de la Frontera, AMJF, donde se puede consultar.

-Estrade Camúñez, J. (1942): Memoria del Laboratorio Municipal de Higiene en 1941. Ayuntamiento de Jerez de la Frontera. Imprenta Municipal: Jerez. (Documento cedido por Manuel S. Estrade Pando al Archivo Municipal de Jerez de la Frontera, AMJF, donde se puede consultar).

-Estrade Camúñez, J. (1943): Memoria del Laboratorio Municipal de Higiene en 1942. Ayuntamiento de Jerez de la Frontera. Imprenta Municipal: Jerez. (Documento cedido por Manuel S. Estrade Pando al Archivo Municipal de Jerez de la Frontera, AMJF, donde se puede consultar).

-Estrade Camúñez, J. [1944]: Memoria del Laboratorio Municipal de Higiene en 1943. Ejemplar mecanografiado. Ayuntamiento de Jerez de la Frontera. 
Imprenta Municipal: Jerez.

(Documento cedido por Manuel S. Estrade Pando al Archivo Municipal de Jerez de la Frontera, AMJF, donde se puede consultar).

-Estrade Camúñez, J. (1945): Memoria del Laboratorio Municipal de Higiene en 1944. Ayuntamiento de Jerez de la Frontera. Imprenta Municipal: Jerez. (Documento cedido por Manuel S. Estrade Pando al Archivo Municipal de Jerez de la Frontera, AMJF, donde se puede consultar).

-Estrade Camúñez, J. (1946): Memoria del Laboratorio Municipal de Higiene en 1945. Ayuntamiento de Jerez de la Frontera. Imprenta Municipal: Jerez. (Documento cedido por Manuel S. Estrade Pando al Archivo Municipal de Jerez de la Frontera, AMJF., donde se puede consultar).

-Estrade Camúñez, J. (1947): Memoria del Laboratorio Municipal de Higiene en 1946. Ayuntamiento de Jerez de la Frontera. Imprenta Municipal: Jerez. (Documento cedido por Manuel S. Estrade Pando al Archivo Municipal de Jerez de la Frontera, AMJF, donde se puede consultar)

-Estrade Camúñez, J. [1959]: Memoria del Laboratorio Municipal de Higiene. Ejemplar mecanografiado. Ayuntamiento de Jerez de la Frontera (Documento cedido por Manuel S. Estrade Pando al Archivo Municipal de Jerez de la Frontera, AMJF, donde se puede consultar.

-Fuejo García, D. (1942): Tifus exantemático. Normas para las empresas. Boletín Oficial de la Provincia de Cádiz: 186 (18-VIII), 2.

-Fuejo, Donato [1943]: Informe sobre la epidemia de "Tifus Exantemático" en la provincia, que presenta el Jefe de Sanidad, Dr. D. Donato Fuejo". Cádiz: Jefatura Provincial de Sanidad. Fuente:
Biblioteca de Andalucía. Sucursal:

Biblioteca de Andalucía (Granada).

-Legajo 1.169, Expediente 24769. Establecimiento de una Central de Desinsectación (Archivo Municipal de Jerez de la Frontera, AMJF).

-Legajo 1.174, Expediente 24.845 (Beneficencia y Sanidad). Construcción de barracones (Archivo Municipal de Jerez de la Frontera, AMJF).

-Libro Cementerio 138 (1939-1942) (Archivo Municipal de Jerez de la Frontera, AMJF)

-Máximo Ruiz, P. [1937]: Memoria de la Campaña del año 1937. Legajo 1.048, Expediente 22.698 (Archivo Municipal de Jerez de la Frontera, AMJF).

-Palanca, J.A. (1943): Las epidemias de la posguerra. Madrid: Real Academia de Medicina (Archivo de Francisco Herrera Rodríguez).

-Protocolo Municipal 663-1941. Cementerio, Alcaldía y Beneficencia (Archivo Municipal de Jerez de la Frontera, AMJF).

-Protocolo Municipal 718-1941. Cementerio, Alcaldía y Beneficencia (Archivo Municipal de Jerez de la Frontera, AMJF).

-Protocolo Municipal 730 (antigua signatura 676)-1941. Documentos de Alcaldía (Archivo Municipal de Jerez de la Frontera, AMJF).

-Reseña estadística de la provincia de Cádiz (1957). Presidencia del Gobierno. Madrid: Instituto Nacional de Estadística (Biblioteca Municipal José Celestino Mutis de Cádiz).

-Servicios Centrales de Higiene Infantil. Disposiciones Sanitarias dictadas durante los años 1939 y 1940 que mayor interés ofrecen para los Médicos Puericultores (1941). Ministerio de la Gobernación. 
Revista científica de la Asociación de Historia y Antropología de los Cuidados (Universidad de Alicante)

Dirección General de Sanidad. Sección de Puericultura, Maternología e Higiene Escolar (Archivo Francisco Herrera Rodríguez, FHR).

\section{BIBLIOGRAFÍA}

Abella, R. (1996). La vida cotidiana bajo el régimen de Franco. Madrid: Editorial Temas de Hoy.

Arbelo Curbelo, A. (1962). La mortalidad de la infancia en España, 1901-1950. Madrid: CSIC.

-Arco Blanco del, M.A. (2006). Morir de hambre. Autarquía, escasez y enfermedad en la España del primer franquismo. Pasado y Memoria. Revista de Historia Contemporánea, 5, 241258.

-Barciela, C. (2000). El mercado negro de productos agrarios en la posguerra, 1939-1953". En: Fontana, J. (ed.). España bajo el franquismo (pp. 192205). Barcelona: Crítica.

Bejarano, F. (2004). El Jerez de los bodegueros. Madrid: Andalucía Abierta.

Bernabeu-Mestre, J. (2002). Madres y enfermeras. Demografía y salud en la política poblacionista del primer franquismo, 1939-1950. Revista de Demografia Histórica, XX, I, 123-143.

Bernabeu-Mestre, J., Caballero Pérez, P., Galiana Sánchez, M.E., Nolasco Bonmatí (2006). Niveles de vida y Salud en la España del primer franquismo: las desigualdades en la mortalidad infantil. Revista de Demografía Histórica, XXIV, I, 181201.

Bosch Marín, J. (1942). La asistencia sanitaria a la madre y al niño. Ministerio de la Gobernación. Dirección General de Sanidad. Sección de Puericultura, Maternología e

Higiene Escolar.

Bosch Marín, J. (1943). Trabajo, maternidad y lactancia. Madrid: Publicaciones del Instituto Nacional de Previsión.

Caballero Bonald, J.M. (1995). Tiempo de guerras perdidas. Barcelona: Editorial Anagrama.

Caro Cancela, D. (1999). Jerez Contemporáneo (siglos XIX y XX). En: Caro Cancela, D. (1999). Historia de Jerez de la Frontera. El Jerez moderno y contemporáneo (pp. 195-438). Cádiz: Servicio de Publicaciones de la Universidad de Cádiz.

Clavero, G., y Pérez Gallardo, F. (1941). Tifus exantemático. Etiología, Clínica, Profilaxis. Madrid: Gráficas Afrodisio Aguado, S.A.

Conde González, Ma . C. (2003). La población de Jerez de la Frontera en los inicios del régimen liberal burgués. Cádiz: Servicio de Publicaciones de la Universidad de Cádiz y Servicio de Publicaciones del Ayuntamiento de Jerez.

Cura, Ma. I., del y Huertas, R. (2007). Alimentación y enfermedad en tiempos de hambre. España, 1937-1947. Madrid: Consejo Superior de Investigaciones Científicas.

Eslava Galán, J. (2010). Los años del miedo. La nueva España (1939-1952). Barcelona: Editorial Planeta.

Estrade Pando, M.S. (2017). "El Dr. D. José Estrade Camúñez y el Laboratorio Municipal de Higiene". La Alcubilla. Boletín Digital de Historia de Jerez, 3, 2-4.

-García Delgado, J.L. (2000): Estancamiento industrial e intervencionismo económico durante el primer franquismo. En: Fontana, J. 
(ed.). España bajo el franquismo (pp. 170-191). Barcelona: Crítica.

García Ferrandis, X., y Martínez Vidal, A. (2017). Salud Pública y espacio urbano en el primer franquismo: la epidemia de tifus exantemático en la ciudad de Valencia (1941-1943). En: Zarzoso, A. y Arrizabalaga, J. (ed.). Al servicio de la salud humana: la Historia de la Medicina ante los retos del siglo XXI (pp. 83-88). XVII Congreso de la Sociedad Española de Historia de la Medicina. Sant Feliu de Guíxols (Girona), 15-17 de junio de 2017. Sant Feliu de Guíxols: Sociedad Española de Historia de la Medicina de Catalunya, Museu d'Historia de Sant Feliu de Guixols, Institució Milá i Fontanals (CSIC).

García Ferrandis, X., y Martínez-Vidal, A. (2019). Salud pública, espacio urbano y exclusión social en la España de la posguerra: la epidemia de tifus exantemático en la ciudad de Valencia, 1941-1943. História, Ciencias, SaúdeManguinhos, 26,2. Recupereado de https://doi.org/10.1590/50104-

59702019000200005 (Consultado el 19 marzo de 2020).

García del Real, E. (1933): Notas a propósito de la historia del tifus exantemático. Madrid: Real Academia Nacional de Medicina.

Gómez Redondo, R. (1992). La mortalidad infantil española en el siglo XX. Madrid: Siglo XXI de España editores.

Haagen, E. (1942). Enfermedades del hombre producidas por los virus. Madrid.

-Harrison, J. (1991): Historia económica de la España contemporánea. Barcelona: Vicens bolsillo.

Herrera-Rodríguez, F. (1997). El tifus exantemático en Cádiz (1940-1945). En: Herrera, F. Crisis y medidas sanitarias en Cádiz (1898-1945) (pp. 137-179 y pp. 190-197). Zaragoza: Universidad de Zaragoza. Recuperado de

rodin.uca.es/xmlui/handle/10498/1822

8 (Consultado el 20 de marzo de 2020).

Herrera-Rodríguez, F. (2000). La situación sanitaria en la provincia de Cádiz en el siglo XX. En: Ramos Santana, A. (coord.). Cádiz. La provincia en el siglo $X X$ (pp. 177-186). Cádiz: Fundación Provincial de Cultura. Diputación Provincial de Cádiz.

Herrera-Rodríguez, F. (2001). El Colegio Oficial de Médicos de la provincia de Cádiz en la Posguerra. En Cabrera Afonso, J.R. y Herrera Rodríguez, F. (dirs.). El Excmo. Colegio Oficial de Médicos de la provincia de Cádiz en el siglo $X X$. Conmemoración de su Centenario (1901-2001) (pp. 211-230). Cádiz: Excmo. Colegio Oficial de Médicos.

Herrera-Rodríguez, F. (2005). La sanidad municipal en el Cádiz de la posguerra. Cádiz: Real Academia de Medicina y Cirugía de Cádiz.

Herrera-Rodríguez, F. (2008). Las enfermedades en el Cádiz de la posguerra. Enfermería Gaditana, 8, 3435.

Herrera-Rodríguez, F. (2015). Una revisión de Pedro Rodrigo Sabalette sobre la poliomielitis (1948). Cultura de los Cuidados, 41, 56-70.

Herrera-Rodríguez, F. (2018). Gerardo Diego y los Juegos Florales en honor a San Juan de Dios en la revista 'Paz y Caridad' (Granada, 1950)". Cultura de los Cuidados, 52, 16-39.

Herrera-Rodríguez, F. (2019). Nota sobre un homenaje a Pío del Río Hortega en la 'Revista de Medicina y Biología' de Cádiz (1926). Llull, 86, 327-340. 
Revista científica de la Asociación de Historia y Antropología de los Cuidados (Universidad de Alicante)

Jiménez Lucena, I. (1990). El tifus en la Málaga de la posguerra. Un estudio históricomédico en torno a una enfermedad colectiva. Málaga: Universidad de Málaga.

Jiménez Lucena, I. (1994). El tifus exantemático de la posguerra española (1939-1943). El uso de una enfermedad colectiva en la legitimación del $<<$ Nuevo Estado $>>$. Dynamis, 14, 185198.

Juliá, S. (2008). Edad Contemporánea. En: Valdeón, J., Pérez, J., Juliá, S. Historia de España (pp. 526-530). Madrid: Austral.

Maradona Hidalgo, J.A. (2010). Historia de las enfermedades infecciosas. Asturias: Universidad de Oviedo.

Marín-Paz, A.J. (2017). Mortalidad y estudio sociosanitario de Vejer de la Frontera (1900-1950). Dos tomos. Tesis doctoral inédita: Universidad de Cádiz.

Mariscal Trujillo, A. (2001) La Sanidad Jerezana 1800-1975 (Apuntes históricos). Jerez de la Frontera: Editorial Eje.

Martín Salazar, M. (1916). Profilaxis del tifus exantemático. Madrid.

Marset Campos, P., Rodríguez Ocaña, E., Sáez Gómez, J.M. (1998). La Salud Pública en España. En: Martínez Navarro, F. y colaboradores. Salud Pública (pp. 41 y ss.). Madrid: McGraw-Hill-Interamericana de España S.A.V.

Miguel Salanova, S. (2017). La ciudad frente a la epidemia. El tifus exantemático en Madrid a principios del siglo XX. Stud. His. $H^{a}$. Cont., 35, 405-444.

Millán Chivite, J.L. (1993). Cádiz siglo XX. Del Cádiz hundido al Cádiz que resurge (1898-1979). Madrid: Editorial Silex.

Navarro García, R. (dir.). (2002). Análisis de la sanidad en España a lo largo del siglo XX. Madrid: Instituto de Salud Carlos III.

Olagüe de Ros, G., y Paredes Salido, F. (1983). Análisis histórico de una revista isleña del siglo $\mathrm{XX}$ : La Medicina Práctica (1902-1915). Su aportación a la Medicina y a la Farmacia de la época. Medicina Militar, 39, 4, 76-79.

Orellana González, C. (1996). Fuentes documentales básicas para la historia de la sanidad y la hospitalidad jerezanas (siglos XV-XX). El caso del Hospital Municipal de Santa Isabel. Revista de Historia de Jerez, 2, 71-82.

Orozco Acuaviva, A. (1981). Bibliografía Médico-Científica gaditana. Cádiz: Obra Cultural "Casino Gaditano".

Palanca y Martínez-Fortún, J.A. (1943). Las epidemias de la postguerra. Madrid: Real Academia de Medicina.

Pascua, M. (1934). Mortalidad específica en España. I. Cálculo de Poblaciones. Madrid: Publicaciones Oficiales de la Comisión Permanente de Investigaciones Sanitarias.

Quintana, P. de la (1942). Tifus exantemático. Etiología, Epidemiología y Profilaxis. Madrid.

Rodríguez Ocaña, E. (2007). Carlos María Cortezo Prieto (1850-1933) y el tifus exantemático: un descubrimiento inexistente. En: Campos, R., Montiel, L., Huertas, R. (coords.). Medicina, Ideología e Historia en España (siglos XVI-XXI) (pp. 125-134). Madrid: CSIC.

Rodríguez Ocaña, E. (2017). Tifus y laboratorio en la España de la posguerra. Dynamis, 37, 2, 489-515. 
Cultura de los Cuidados

Ruiz Mata, J. (2010). Breve Historia de Jerez de la Frontera. Cádiz: Tierra de Nadie Editores.

Suárez Japón, J.M. (2014) Sinelo Calorró: Conversaciones con Manuel Morao. Cádiz: Servicio de Publicaciones de la Diputación de Cádiz.
Tamames, R. (1985). Una idea de España. Ayer, hoy y mañana. Barcelona: Plaza \& Janés, S.A.

Terán Reyes, F.J. (2012). Las cartillas de racionamiento, los fielatos y el estraperlo. Historia reciente Aljaranda, 86, 10-19.

Vázquez Montalbán, M. (1986). Crónica sentimental de España. Madrid: Espasa Calpe.

\section{TABLA 1: Habitantes de Jerez de la Frontera (1940-1950)}

Fuente: Población 1859-1960 (Legajo 3877, Expediente 33949. A.M.J.F.)

\begin{tabular}{|c|c|}
\hline Años & Habitantes de Jerez de la Frontera \\
\hline $\mathbf{1 9 4 0}$ & 89.525 \\
\hline $\mathbf{1 9 4 1}$ & 89.784 \\
\hline $\mathbf{1 9 4 2}$ & 90.625 \\
\hline $\mathbf{1 9 4 3}$ & 92.056 \\
\hline $\mathbf{1 9 4 4}$ & 92.998 \\
\hline $\mathbf{1 9 4 5}$ & 99.811 \\
\hline $\mathbf{1 9 4 6}$ & 100.603 \\
\hline $\mathbf{1 9 4 7}$ & 101.998 \\
\hline $\mathbf{1 9 4 8}$ & 104.958 \\
\hline $\mathbf{1 9 4 9}$ & 107.040 \\
\hline $\mathbf{1 9 5 0}$ & 107.770 \\
\hline
\end{tabular}


Revista científica de la Asociación de Historia y Antropología de los Cuidados (Universidad de Alicante)

TABLA 2: Defunciones y Tasas de Mortalidad General en Jerez de la Frontera (19371946)

Fuente: Datos tomados de José Estrade Camúñez: Memorias del Laboratorio Municipal de Higiene, (AMJF). Excepto 1943: Cálculo personal, teniendo en cuenta la población del citado año expresada en tabla 1 y el número de fallecidos registrados en los libros de cementerio del referido año (AMJF).

\begin{tabular}{|c|c|c|}
\hline AÑOS & DEFUNCIONES & $\begin{array}{c}\text { TMG } \\
\text { (Defunciones } \\
\text { por mil } \\
\text { habitantes) }\end{array}$ \\
\hline 1937 & 1.340 & 18,7 \\
\hline 1938 & 1.466 & 20,4 \\
\hline 1939 & 1.372 & 18,7 \\
\hline 1940 & 1.223 & 16,9 \\
\hline 1941 & 2.303 & 25,7 \\
\hline 1942 & 1.486 & 16,3 \\
\hline 1943 & 1.464 & 15,9 \\
\hline 1944 & 1.239 & 13,8 \\
\hline 1945 & 1.062 & 11,8 \\
\hline 1946 & 1.163 & 12,9 \\
\hline
\end{tabular}

TABLA 3: Tasas de Mortalidad General de Cádiz y la provincia de Cádiz (1940-1945). Defunciones por mil.

Fuente: Herrera Rodríguez, 1997. Elaboración a partir de los libros del Movimiento Natural de la Población (1940, 1941, 1942, 1943, 1944, 1945)

\begin{tabular}{|c|c|c|}
\hline AÑOS & TMG Cádiz capital & TMG de la provincia de Cádiz \\
\hline $\mathbf{1 9 4 0}$ & 20,04 & 16,78 \\
\hline $\mathbf{1 9 4 1}$ & 31,43 & 27,59 \\
\hline $\mathbf{1 9 4 2}$ & 20,42 & 18,33 \\
\hline $\mathbf{1 9 4 3}$ & 15,22 & 14,63 \\
\hline $\mathbf{1 9 4 4}$ & 15,43 & 13,79 \\
\hline $\mathbf{1 9 4 5}$ & 15,01 & 12,51 \\
\hline
\end{tabular}


TABLA 4: Defunciones y Tasas de Mortalidad General en Jerez de la Frontera (19301937). Defunciones por mil.

Fuente:

Pedro Máximo Ruiz: Memoria de la Campaña del año 1937. Legajo 1.048, Expediente 22.698 (Archivo Municipal de Jerez de la Frontera)

\begin{tabular}{|c|c|c|}
\hline AÑOS & DEFUNCIONES & TMG (por mil) \\
\hline $\mathbf{1 9 3 0}$ & 1519 & 20,81 \\
\hline $\mathbf{1 9 3 1}$ & 1348 & 18,46 \\
\hline $\mathbf{1 9 3 2}$ & 1345 & 18,66 \\
\hline $\mathbf{1 9 3 3}$ & 1499 & 20,80 \\
\hline $\mathbf{1 9 3 4}$ & 1350 & 18,73 \\
\hline $\mathbf{1 9 3 5}$ & 1520 & 21,51 \\
\hline $\mathbf{1 9 3 6}$ & 1373 & 19,05 \\
\hline $\mathbf{1 9 3 7}$ & 1242 & 17,23 \\
\hline
\end{tabular}

TABLA 5: Casos y defunciones en Jerez de la Frontera. Tifus exantemático. 1941 Fuente: Donato Fuejo, [1943]

\begin{tabular}{|c|c|c|}
\hline MESES & CASOS & DEFUNCIONES \\
\hline Enero & - & - \\
\hline Febrero & - & - \\
\hline Marzo & - & - \\
\hline Abril & - & - \\
\hline Mayo & 53 & 3 \\
\hline Junio & 72 & 14 \\
\hline Julio & 30 & 5 \\
\hline Agosto & 34 & 2 \\
\hline Septiembre & 4 & - \\
\hline Octubre & 1 & - \\
\hline Noviembre & - & - \\
\hline Diciembre & - & - \\
\hline TOTAL & 194 & 24 \\
\hline
\end{tabular}


TABLA 6: Casos y defunciones en Jerez de la Frontera. Tifus exantemático. 1942 Fuente: Fuejo, [1943]

\begin{tabular}{|c|c|c|}
\hline MESES & CASOS & DEFUNCIONES \\
\hline Enero & - & - \\
\hline Febrero & - & - \\
\hline Marzo & 1 & - \\
\hline Abril & 6 & 1 \\
\hline Mayo & 4 & - \\
\hline Junio & 2 & - \\
\hline Julio & 10 & 1 \\
\hline Agosto & 2 & - \\
\hline Septiembre & - & - \\
\hline Octubre & - & - \\
\hline Noviembre & - & - \\
\hline Diciembre & - & 2 \\
\hline TOTAL & 25 & \\
\hline & & \\
\hline
\end{tabular}


TABLA 7

Total defunciones por infecciosas y defunciones por tuberculosis en Jerez de la Frontera (1937-

1959) Fuente: Estrade Camúñez, 1959

\begin{tabular}{|c|c|c|}
\hline Años & $\begin{array}{l}\text { Total defunciones } \\
\text { por enfermedades } \\
\text { infecciosas }\end{array}$ & Defunciones por tuberculosis \\
\hline 1937 & 379 & 109 \\
\hline 1938 & 141 & 138 \\
\hline 1939 & 504 & 134 \\
\hline 1940 & 464 & 143 \\
\hline 1941 & 653 & 156 \\
\hline 1942 & 509 & 194 \\
\hline 1943 & 444 & 173 \\
\hline 1944 & 468 & 191 \\
\hline 1945 & 417 & 156 \\
\hline 1946 & 457 & 195 \\
\hline 1947 & 514 & 213 \\
\hline 1948 & 422 & 187 \\
\hline 1949 & 480 & 212 \\
\hline 1950 & 420 & 191 \\
\hline 1951 & 421 & 207 \\
\hline 1952 & 235 & 107 \\
\hline 1953 & 241 & 87 \\
\hline 1954 & 160 & 88 \\
\hline 1955 & 104 & 79 \\
\hline 1956 & 112 & 90 \\
\hline 1957 & 112 & 79 \\
\hline 1958 & 95 & 70 \\
\hline 1959 & 69 & 59 \\
\hline
\end{tabular}

TABLA 8: Casos de paludismo en Jerez de la Frontera (1943-1953)

Fuente: Estrade Camúñez, 1959

\begin{tabular}{|c|c|c|c|c|c|}
\hline AÑNOS & CASOS & & & & \\
\hline 1943 & 6513 & 1948 & 1239 & 1953 & 11 \\
\hline 1944 & 3122 & 1949 & 621 & & \\
\hline 1945 & 2145 & 1950 & 124 & & \\
\hline 1946 & 1605 & 1951 & 44 & & \\
\hline 1947 & 2028 & 1952 & 51 & & \\
\hline
\end{tabular}


APÉNDICE DOCUMENTAL No 1

MEMORIA DEL LABORATORIO MUNICIPAL DE HIGIENE EN 1941 (Redactada por el Director D. José Estrade Camúñez). Ayuntamiento de Jerez de la Frontera. Jerez, 1942

\section{SERVICIO EPIDEMIOLÓGICO}

Fichas epidemiológicas de enfermos

Número de casos registrados en este Centro durante el año

(pp. 10-17)

-Tuberculosis pulmonar: 7

-Fiebre de Malta: 1

-Gripe: 3

-Difteria: 2

-Coqueluche: 2

-Septicemia puerperal: 1

-Varicela: 5

-Fiebre tifoidea: 240

-Tifus exantemático: 162

-Parálisis infantil: 1

Número total en el año, 424.

Coeficiente de las enfermedades infecciosas

Proporción por cada 10.000 habitantes 
-Tuberculosis pulmonar: 0,707

-Fiebre de Malta: 0,101

-Gripe: 0,303

-Difteria: 0,202

-Coqueluche: 0,202

-Septicemia puerperal: 0,101

-Varicela: 0,505

-Fiebre Tifoidea: 24,240

-Tifus exantemático: 16,160

-Parálisis infantil: 0,101

"Estos casos están tomados de los partes que tramita a este Centro el Sr. Jefe de los Servicios Sanitarios, para que se tomen las medidas profilácticas en cada caso, que como se ve son muy inferiores a las cifras de mortalidad".

MORTALIDAD EN GENERAL

\begin{tabular}{|c|c|c|}
\hline MESES & $\begin{array}{c}\text { POR ENFERMEDADES } \\
\text { INFECCIOSAS }\end{array}$ & $\begin{array}{c}\text { POR ENFERMEDADES NO } \\
\text { INFECCIOSAS }\end{array}$ \\
\hline Enero & 70 & 187 \\
\hline Febrero & 69 & 141 \\
\hline Marzo & 57 & 169 \\
\hline Abril & 60 & 131 \\
\hline Mayo & 59 & 84 \\
\hline Junio & 71 & 176 \\
\hline Julio & 54 & 199 \\
\hline Agosto & 54 & 131 \\
\hline Septiembre & 35 & 75 \\
\hline Octubre & 35 & 97 \\
\hline Noviembre & 60 & 141 \\
\hline Diciembre & 29 & 120 \\
\hline
\end{tabular}

Número total de defunciones por enfermedades infecciosas: 653 
Revista científica de la Asociación de Historia y Antropología de los Cuidados (Universidad de Alicante)

Número total de defunciones por enfermedades no infecciosas: 1.651

Número total de defunciones en el año: 2.303

\section{COEFICIENTE DE MORTALIDAD}

(Proporción por cada 10.000 habitantes)

Coeficiente anual en enfermedades infecciosas: 72,923

Coeficiente anual en enfermedades no infecciosas: 184,398

Coeficiente anual en enfermedades de mortalidad

(Proporción por cada 10.000 habitantes): 257,321

\section{MORTALIDAD INFANTIL}

Fallecidos menores de un año por cada 1.000 nacidos vivos. Media en el año:

211,76

Defunciones de menores de un año:

-Infecciosas: 43. -No infecciosas: 322. -Total: 365.

Defunciones de 1 a 4 años:

-Infecciosas: 26. -No infecciosas: 44. -Total: 70.

\section{APÉNDICE DOCUMENTAL No 2}

MEMORIA DEL LABORATORIO MUNICIPAL DE HIGIENE EN 1942

(Redactada por el director D. José Estrade Camúñez).

Ayuntamiento de Jerez de la Frontera. Tipografía Municipal. Jerez, 1943

\section{SERVICIO EPIDEMIOLÓGICO}

Fichas epidemiológicas de enfermos

Número de casos registrados en este Centro durante el año

(pp. 18-25)

-Fiebre de Malta: 2

-Difteria: 8

-Fiebre tifoidea: 132 
-Sarampión: 46

-Varicela: 4

-Tifus exantemático: 19

-Parálisis infantil: 5

Número total en el año, 216

Coeficiente de las enfermedades infecciosas

Proporción por cada 10.000 habitantes

-Fiebre de Malta: 0,22

-Difteria: 0,89

-Fiebre Tifoidea: 14,72

-Sarampión: 5,13

-Varicela: 0,44

-Tifus exantemático: 2,11

-Parálisis infantil: 0,56

MORTALIDAD EN GENERAL

\begin{tabular}{|c|c|c|}
\hline MESES & $\begin{array}{c}\text { POR ENFERMEDADES } \\
\text { INFECCIOSAS }\end{array}$ & $\begin{array}{c}\text { POR ENFERMEDADES NO } \\
\text { INFECCIOSAS }\end{array}$ \\
\hline Enero & 46 & 96 \\
\hline Febrero & 62 & 117 \\
\hline Marzo & 60 & 90 \\
\hline Abril & 34 & 58 \\
\hline Mayo & 35 & 60 \\
\hline Junio & 34 & 81 \\
\hline Julio & 33 & 97 \\
\hline Agosto & 41 & 99 \\
\hline Septiembre & 34 & 65 \\
\hline Octubre & 43 & 63 \\
\hline Noviembre & 41 & 72 \\
\hline Diciembre & 46 & 61 \\
\hline
\end{tabular}

Número total de defunciones por enfermedades infecciosas: 509.

Número total de defunciones por enfermedades no infecciosas: 959.

Número total de defunciones en el año: 1.468.

\section{COEFICIENTE DE MORTALIDAD}

(Proporción por cada 10.000 habitantes)

Coeficiente anual en enfermedades infecciosas: 107,11 
Revista científica de la Asociación de Historia y Antropología de los Cuidados (Universidad de Alicante)

Coeficiente anual en enfermedades no infecciosas: 56,84

Coeficiente anual en enfermedades de mortalidad

(Proporción por cada 10.000 habitantes): 163,95

\section{MORTALIDAD INFANTIL}

Fallecidos menores de un año por cada 1.000 nacidos vivos. Media en el año:

123,23

Defunciones de menores de un año:

-Infecciosas: 46. -No infecciosas: 163. -Total: 209.

Defunciones de 1 a 4 años:

-Infecciosas: 52. -No infecciosas: 69. -Total: 121.

\section{APÉNDICE DOCUMENTAL No 3}

Informe de Salvador Dastis sobre los datos estadísticos recopilados durante el año de 1942 en la Oficina Municipal de Sanidad, así como la relación de algunos de los servicios que se han prestado en ella. Al Sr. Alcalde de la ciudad (firmado en Jerez de la Frontera, 28 de enero de 1943, dirigido al Alcalde y con sello de la Subdelegación de Medicina del Distrito Sanitario de Jerez de la Frontera) (Legajo 1.169, Expediente 24770, Archivo Municipal de Jerez de la Frontera, AMJF)

Tengo el honor de trasladar a V.S. datos estadísticos recopilados durante el año de 1942 en la Oficina Municipal de Sanidad, así como relación de algunos servicios que se han prestado en ella.

Número de habitantes según censo de 1940: 89.525

Nacidos vivos: $2.125=23,73 \mathrm{o} / \mathrm{oo}$

Nacidos muertos: 142

Defunciones: $1.548=17,29 \mathrm{o} / \mathrm{oo}$

Aumento de población: 577

Casamientos: 602

\section{Causas de defunción}

Enfermedades del aparato circulatorio: 259

Enfermedades del aparato respiratorio: 202

Enfermedades del aparato urinario: 91

Enfermedades del aparato gastrointestinal: 166

Tuberculosis: 190 
Meningitis: 51

Cáncer y otros tumores malignos: 145

Atrepsia: 109

Fiebre tifoidea: 23

Tifus exantemático: 2

Gripe: 44

Septicemia puerperal: 5

Sarampión: 4

Coqueluche: 9

Difteria: 5

Paludismo: 6

Accidentes, suicidios y muertes violentas: 46

Progresos de la edad: 97

Causas diversas: 94

TOTAL: 1.548

\section{Edad de los fallecidos}

Menores de un año: 237

De 1 a 10 años: 152

De 10 a 60 años: 474

De 60 a 80 años: 498

De más de 80 años: 187

TOTAL: 1.548

La edad máxima registrada en los certificados es de 103 años.

Casos de enfermedades infecto-contagiosas, comunicados por los profesores médicos, sin incluir los asistidos en el Dispensario Antituberculoso

Paludismo: 3.943

Coqueluche: 1.138

Gripe: 1.006

Sarampión: 493

Tuberculosis: 240

Fiebre tifoidea: 207

Varicela: 62 
Septicemia puerperal: 51

Tifus exantemático: 26

Difteria: 20

Fiebre de Malta: 8

Tracoma: 5

Parálisis infantil: 5

TOTAL: 7.204

Inspección de viviendas para expedir la Célula de Habitabilidad: 586

Inspección de viviendas por denuncias de inquilinos: 271

Inspección de locales por apertura o traslado de industrias: 191

Inspección de Hoteles, pensiones, paradores y casas de dormir: 58

Inspección de Escuelas, barberías, despachos de comestibles, de verduras, de vinos, café y varios: 543

Informes en obras de nueva construcción solicitados por la Alcaldía: 20

Oficios e informes a la Alcaldía, Jefe Provincial de Sanidad y de Jefe de los servicios municipales: 455

"Por Dios por España y su Revolución Nacional Sindicalista".

Jerez de la Frontera 28 de enero de 1943.

Firmado y rubricado por Salvador Dastis. 